\title{
Antianxiety and Antidepressive Behavior Produced by Physiological Estradiol Regimen may be Modulated by Hypothalamic-Pituitary-Adrenal Axis Activity
}

\author{
Alicia A Walf' and Cheryl A Frye ${ }^{*, 1,2,3}$ \\ 'Department of Psychology, The University at Albany - SUNY, Albany, NY, USA; ${ }^{2}$ Department of Biological Sciences, The University at \\ Albany - SUNY, Albany, NY, USA; ${ }^{3}$ The Center for Neuroscience Research, The University at Albany — SUNY, Albany, NY, USA
}

\begin{abstract}
Variations in estradiol $\left(E_{2}\right)$ may influence expression of stress-related anxiety and depression symptoms among women. Effects of $E_{2}$ and stress on anxiety and depressive behavior were investigated using an animal model. $E_{2}$ was administered subcutaneously $(0,2,5,10,20$, $50 \mu \mathrm{g} / \mathrm{rat}$ ) to ovariectomized rats 2 days before testing. In experiment I, open field (anxiety), elevated plus maze (anxiety), or forced swim test (depressive) behavior was evaluated following 20 min of restraint or no such stressor. Rats administered 5 or $10 \mu \mathrm{g} E_{2}$, which produced physiological plasma $E_{2}$ concentrations, showed significantly less anxiety and depressive behavior and lower corticosterone levels compared to vehicle, lower, or higher $E_{2}$ dosages. Restraint stress prior to behavioral testing attenuated the antianxiety and antidepressive effects of 5 or $10 \mu g E_{2}$. In experiment 2, effects of adrenalectomy or sham surgery and vehicle or corticosterone replacement in their drinking water on behavior and neuroendocrine measures of rats administered 0 , 10 , or $50 \mu \mathrm{g} E_{2}$ were examined. $E_{2}, 10 \mu g$, compared to vehicle or $50 \mu \mathrm{g}$, reduced anxiety and depressive behavior of sham and adrenalectomized rats administered the low dosage of corticosterone, but not vehicle or the high dosage of corticosterone, suggesting that there may be an optimal level of corticosterone necessary for $E_{2}$ to exert these effects. Together, these data suggest that $E_{2}$ may have dose-dependent effects on anxiety and depressive behavior of female rodents, which may depend on the tone of the hypothalamic-pituitary-adrenal axis. Neuropsychopharmacology (2005) 30, I 288-I30I, advance online publication, 9 March 2005; doi: I 0.I 038/sj.npp. I 300708
\end{abstract}

Keywords: estrogen; sex differences; hypothalamic-pituitary-adrenal axis; mood; restraint stress; porsolt

\section{INTRODUCTION}

Gender differences in anxiety and depressive disorders favor males. Women are more likely than men to develop anxiety disorders (Seeman, 1997). Women, compared to men, are twice as likely to experience depression and their depressive episodes are longer-lasting and recur more often (Earls, 1987; Nolen-Hoeksema, 1987). These gender differences suggest that sex-linked factors, such as gonadal steroids, may influence their etiology and/or expression (Young, 1998; Young and Korszun, 2002).

The ovarian hormone estradiol $\left(\mathrm{E}_{2}\right)$ may influence incidence of, or negative symptomology associated with, mood disorders. Gender differences in depression emerge at puberty and disappear after menopause (Kessler and Walters, 1998; Lewinsohn et al, 1998; Weissman and

* Correspondence: Dr CA Frye, Social Science 220, The University at Albany-SUNY, Albany, NY I2222, USA, Tel: + 518442 4836,

Fax: + 518442 4247, E-mail: cafrye@albany.edu

Received I April 2004; revised 14 January 2005; accepted 20 January 2005

Online publication: 31 January 2005 at http://www.acnp.org/citations/ NPP0 I 3 10504/50/default.pdf
Olfson, 1995). In contrast, the incidence of generalized anxiety disorder is doubled in older, postmenopausal women (Bebbington, 1978; Jenkins, 1987; Weissman and Klerman, 1977; Wittchen and Hoyer, 2001). There are reports of negative symptomology associated with anxiety and depression being greater perimenstrually, postpartum, and after menopause or oophorectomy, when women's $\mathrm{E}_{2}$ levels would be expected to be lower (Torizuka et al, 2000). Among depressed women, plasma $\mathrm{E}_{2}$ levels are significantly lower than is observed in nondepressed women (Young et al, 2000). $\mathrm{E}_{2}$-replacement therapy to perimenopausal women with depression may provide mood benefits (Cohen et al, 2003; Schmidt et al, 2000; Soares et al, 2001). As well, postmenopausal women taking $\mathrm{E}_{2}$-replacement therapy had lower depression scores on the Profile of Mood States task than did age-matched women who were not on $\mathrm{E}_{2}$-replacement therapy (Miller et al, 2002). However, some women with anxiety disorders report less anxiety when $E_{2}$ levels are low and/or stable (Schmidt et al, 1998). Although these data suggest that changes in $\mathrm{E}_{2}$ levels may influence anxiety and/or depression, $\mathrm{E}_{2}$ 's role is not completely understood. 
Evidence from animal models also suggests that $E_{2}$ has variable effects on anxiety or depressive behavior of rodents. Rats show less anxiety and depressive behavior during the proestrous phase of the estrous cycle, when $E_{2}$ levels are high, compared to the diestrous phase, when $\mathrm{E}_{2}$ levels are low (Diaz-Veliz et al, 1997; Frye et al, 2000; Marcondes et al, 2001; Mora et al, 1996). Ovariectomy (ovx), removal of the primary source of $E_{2}$, the ovaries, increases anxiety and depressive behavior, and acute, subchronic, or chronic physiological $\mathrm{E}_{2}$-replacement reduces anxiety and depressive behavior of rodents (Bernardi et al, 1989; Bowman et al, 2002; Diaz-Veliz et al, 1997; Estrada-Camarena et al, 2003; Frye and Walf, 2004a; Hilakivi-Clarke, 1996; Luine et al, 1998; Marcondes et al, 2001; Mora et al, 1996; Nomikos and Spyraki, 1988; Rachman et al, 1998; Slater and Blizard, 1976). However, longer $\mathrm{E}_{2}$-replacement regimen and/or a higher $\mathrm{E}_{2}$ dosages may not reduce anxiety and/or depressive behavior (DiazVeliz et al, 1997, 2000; Galea et al, 2002; Martinez-Mota et al, 2000; Mora et al, 1996; Morgan and Pfaff, 2001, 2002; Stoffel and Craft, 2003). Thus, $\mathrm{E}_{2}$ 's effects on anxiety and/or depressive behavior of rodents may depend upon the $\mathrm{E}_{2}$ dosage and/or regimen.

Estradiol may have effects to alter the function of the hypothalamic-pituitary-adrenal axis (HPA). Proestrous rats have increased basal and stress-induced plasma corticosterone levels compared to rats in other stages of the estrous cycle (Carey et al, 1995; Figueiredo et al, 2002; Frye and Bayon, 1999; Raps et al, 1971; Viau and Meaney, 1991). Administration of $E_{2}$ to ovx rats may reduce basal and/or stress-induced corticosterone levels, but administration of higher $\mathrm{E}_{2}$ dosages may increase corticosterone levels (Burgess and Handa, 1992; Carey et al, 1995; Dayas et al, 2000; Kitay, 1963; McCormick et al, 2002; Redei et al, 1994). Differences in HPA reactivity may underlie some affective responses of rodents (Conrad et al, 1997; Maccari et al, 2003; Welberg et al, 2000), but whether $\mathrm{E}_{2}$ 's effects on anxiety and/or depressive behavior may require the HPA is not established.

Given $E_{2}$ 's influence on affective behavior and the HPA, whether $\mathrm{E}_{2}$ may mitigate these behavioral processes in part through actions involving the HPA was of interest. We investigated this by testing the following hypotheses. First, if $\mathrm{E}_{2}$ mediates anxiety (open field, elevated plus maze) and/ or depressive (forced swim test) behavior, then $\mathrm{E}_{2}$ should dose-dependently alter central entries in the open field, open arm time in the plus maze, and/or decrease immobility in the forced swim test. Second, if $E_{2}$ 's effects on anxiety or depressive behavior are mediated by the HPA, then increasing HPA activity with restraint stress before behavioral testing should alter effects of $E_{2}$ for anxiety or depressive behavior and corticosterone levels. Third, if $\mathrm{E}_{2}$ 's effects on anxiety and depressive behavior require HPA feedback, then adrenalectomy (ADX) should attenuate $E_{2}$ 's dose-dependent effects on anxiety and depressive behavior. Fourth, if corticosterone mediates $\mathrm{E}_{2}$ 's effects on anxiety and depressive behavior, then corticosterone replacement would be expected to shift effects of $E_{2}$ in ADX rats. To test these hypotheses, two experiments were performed. In experiment 1 , ovx rats were administered different dosages of $E_{2}(0,2,5,10,20$, or $50 \mu \mathrm{g}) 48 \mathrm{~h}$ before testing in anxiety or depression tasks. Some rats were restraint stressed before testing to determine the effects of activating the HPA on anxiety and depressive behavior, plasma corticosterone and $\mathrm{E}_{2}$ levels. In experiment 2, ovx rats were sham surgerized or ADX and replaced with vehicle, a low, or high dose of corticosterone in their drinking water and administered 0 , 10 , or $50 \mu \mathrm{g} \mathrm{E}_{2} 48 \mathrm{~h}$ before testing. Effects on anxiety and depressive behavior, plasma corticosterone and $\mathrm{E}_{2}$ levels were examined.

\section{MATERIALS AND METHODS}

These methods were preapproved by the Institutional Animal Care and Use Committee at SUNY, Albany.

\section{Animals and Housing}

Female Long-Evans rats $(N=284)$, approximately 55 days old, were obtained from the breeding colony at SUNY, Albany (original stock from Taconic Farms, Germantown, NY). Rats were group housed (4-5 per cage) in polycarbonate cages $(45 \times 24 \times 21 \mathrm{~cm})$ in a temperature-controlled room $\left(21 \pm 1^{\circ} \mathrm{C}\right)$ in The Laboratory Animal Care Facility. The rats were maintained on a $12 / 12 \mathrm{~h}$ reversed light cycle (lights off 0800 hours) with continuous access to Purina Rat Chow and tap water in their cages. To prevent wasting, ADX and sham ADX rats also had continuous access to $0.09 \%$ saline in their cages.

\section{Surgery}

All rats were ovariectomized (ovx) under Rompun (12 mg/ kg; Bayer Corp., Shawnee Mission, KS) and Ketaset $(80 \mathrm{mg} /$ kg; Fort Dodge Animal Health, Fort Dodge, IA) anesthesia 1 week prior to testing. Some rats $(n=118)$ were also bilaterally ADX, 7-10 days post ovx and 1 week before testing.

\section{Estradiol-Priming}

In experiment $1,48 \mathrm{~h}$ before testing, ovx rats were subcutaneously administered the following dosages of $17 \beta$ - $\mathrm{E}_{2}$ (Sigma Chemical Co., St Louis, MO) in sesame oil vehicle: $0,2,5,10,20$, or $50 \mu \mathrm{g} \mathrm{E}_{2}$. In experiment 2 , ovx rats were subcutaneously administered 0,10 , or $50 \mu \mathrm{g} \mathrm{E}_{2} 48 \mathrm{~h}$ before testing. This regimen of $\mathrm{E}_{2} 48 \mathrm{~h}$ prior to testing was used because it mimics the gradual increase in plasma $E_{2}$ levels during the estrous cycle and is commonly employed to induce sexual receptivity in rats (Frye et al, 1998). We have also used this regimen with success in the past to examine $E_{2}$ 's modulation of affective behavior of ovx rats (Frye and Walf, 2004a; Walf and Frye, 2003; Walf, Rhodes, and Frye, 2004)

\section{Restraint Stress}

In experiment 1 , immediately before behavioral testing in the open field, elevated plus maze, or forced swim task, some rats from each $E_{2}$ condition were placed in a plexiglas animal restrainer under a 60 -Watt light for $20 \mathrm{~min}$ or were not stressed before testing (Frye and Orecki, 2002a, b). 


\section{ADX Conditions and Corticosterone Replacement}

To determine completeness of ADX surgery, rats were restrained for $20 \mathrm{~min}$ and tail blood was collected from rats $24 \mathrm{~h}$ following ADX. Plasma corticosterone levels were determined for each rat. Rats with plasma corticosterone levels above typical basal levels (greater than $2.0 \mu \mathrm{g} / \mathrm{dl}$ ) were considered to have incomplete ADX and comprised the sham surgerized condition. Rats were considered to be completely ADX if their plasma corticosterone levels were less than $2.0 \mu \mathrm{g} / \mathrm{dl}$. These ADX rats were randomly assigned to receive vehicle $(0.09 \%$ sodium chloride in water and $<0.01 \%$ ethyl alcohol), $25 \mu \mathrm{g} / \mathrm{ml}$, or $250 \mu \mathrm{g} / \mathrm{ml}$ corticosterone in the same vehicle in their drinking water. These dosages were based on previous findings that replacement of $25 \mu \mathrm{g} / \mathrm{ml}$ corticosterone in drinking water produces basal levels of plasma corticosterone and $250 \mu \mathrm{g} / \mathrm{ml}$ corticosterone produces stress-like plasma corticosterone levels (Glavas et al, 2001; McCormick et al, 2001). Daily average intake of corticosterone were determined for each cage of rats, and basal plasma corticosterone levels were determined in rats 4 days after replacement began, to determine effectiveness of replacement regimen used. ADX rats administered vehicle (ADX + veh group) had corticosterone levels (mean $\pm \mathrm{SD}$ ) below basal levels typically observed in intact rats $(0.7 \pm 1.1 \mu \mathrm{g} / \mathrm{dl})$. ADX rats administered $25 \mu \mathrm{g} / \mathrm{ml}$ corticosterone (ADX + 25 CORT) had corticosterone levels similar to the sham ADX group $(4.3 \pm 9.3$ and $5.2 \pm 9.4 \mu \mathrm{g} / \mathrm{dl}$, respectively) and ADX rats administered $250 \mu \mathrm{g} / \mathrm{ml}$ corticosterone (ADX + 250 CORT) had plasma corticosterone levels of $20.5 \pm 16.8 \mu \mathrm{g} / \mathrm{dl}$.

\section{Behavioral Testing}

Most rats in experiment 1 were tested in all three of the following tasks in the same order once a week for 3 weeks. There were no observable differences in behavior of rats that were only tested in one task, compared to those that were tested in all three tasks. In experiment 2 , all rats were tested once a week for 3 weeks so that each rat was tested in the open field, elevated plus maze, and forced swim task.

Open field. Rats were placed in a brightly lit open field $(76 \times 57 \times 35 \mathrm{~cm})$ and observed for $5 \mathrm{~min}$, while the number of central and peripheral squares entered was recorded (Frye et al, 2000; McCarthy et al, 1995). The percentage of central entries compared to total entries made were determined for each rat (\# of central entries/\# of total entries $\times 100$ ). Central entries are considered an index of antianxiety behavior.

Elevated plus maze. Rats were placed in a brightly lit elevated plus maze and the time spent in the closed and open arms of this maze was recorded for 5 min (Frye et al, 2000; Pellow and File, 1986). The plus maze consisted of four arms $(50 \times 10 \mathrm{~cm})$ that are elevated $50 \mathrm{~cm}$ above the floor; two of these arms are enclosed by $37 \mathrm{~cm}$ high walls. Open arm duration is considered an index of antianxiety behavior.

Forced swim task. Rats were tested in a modified version of the forced swim test (Frye and Walf, 2002; Porsolt $e t$ al,
1977). Rats were placed in a cylindrical container filled with $30 \mathrm{~cm}$ of $30^{\circ} \mathrm{C}$ water. The amount of time the rats spent swimming, struggling, and immobile was recorded for $10 \mathrm{~min}$. Struggling was characterized as the rats' movement in the water, which was typically quick movement of the front paws that break the surface of the water and appear to be attempts to escape the chamber. Swimming was recorded when the rats were engaged in movement of the front and back paws without the front paws breaking the surface of the water. Immobility was defined as an absence of any movement other than those necessary to keep the head and nose above the surface of the water (eg floating). Immobility is considered an index of depressive behavior.

\section{Tissue Collection and Radioimmunoassay}

Tissue collection. In experiment 1, blood was collected from all rats once - either immediately after removal from home cage (no restraint stress and not tested), or after behavioral testing with restraint, or testing with no prior restraint. In experiment 2, blood was collected from all rats on three occasions $-24 \mathrm{~h}$ after ADX, 4 days after corticosteronereplacement, and immediately after elevated plus maze testing. Blood, collected from rats via a small nick in the tip of the tail, was placed in EDTA-containing chilled eppendorfs, centrifuged ( $3000 \mathrm{~g}$ for $20 \mathrm{~min}$ ), and plasma was stored at $-20^{\circ} \mathrm{C}$ until radioimmunoassay (Tomie et al, 2002; Walf and Frye, 2003).

Estradiol radioimmunoassay. In experiment 1, to determine plasma $E_{2}$ levels, plasma samples were pooled from some rats in the same $\mathrm{E}_{2}$ dosage and stress (no stress and not tested, no stress and tested, and restraint stress and tested), which produced 3-8 data points per group. From these samples, there was at least 1 data point for each of the three behavioral tasks so that we could analyze if testing itself altered plasma $E_{2}$ levels of rats. In experiment 2, rats were not stressed, which resulted in larger plasma samples such that $\mathrm{E}_{2}$ could be measured in each rat, yielding 7-12 data points per group. $E_{2}$ was extracted twice with ether, by snap freezing. Following chromatographic separation, pellets were reconstituted in PBS $(\mathrm{pH}=7.4)$. The standard curve was prepared in duplicate $(12.5-1000 \mathrm{pg} / 0.1 \mathrm{ml})$. Standards were added to PBS, with $\mathrm{E}_{2}$ antibody (Dr Niswender, \#244, Colorado State University, Fort Collins, $\mathrm{CO}$ ), and $\left[{ }^{3} \mathrm{H}\right] \mathrm{E}_{2}$ (NET-317, $51.3 \mathrm{ci} / \mathrm{mmol}$; New England Nuclear, Boston, MA, $8000 \mathrm{dpm} / 100 \mathrm{ml}$; Frye and Bayon, 1999; Frye et al, 1996). Assay tubes are incubated at room temperature for $50 \mathrm{~min}$. Dextran-coated charcoal was used to separate bound and free following a 10-min incubation on ice and centrifugation at $3000 \mathrm{~g}$ for $10 \mathrm{~min}$. Supernatant was pipetted into a glass scintillation vial with scintillation cocktail and counted using a Tri-Carb 2000CA Liquid Scintillation Analyzer. Unknowns were interpolated from the standard curve using Assay Zap, a program for radioimmunoassay analyses. The inter- and intra-assay coefficients of variance were 0.08 and 0.10 , respectively.

Corticosterone radioimmunoassay. Corticosterone was measured in each sample collected. Corticosterone was extracted from plasma by heating at $60^{\circ} \mathrm{C}$ for $30 \mathrm{~min}$. Samples were incubated for $60 \mathrm{~min}$ at room temperature 
with $\left[{ }^{3} \mathrm{H}\right]$ corticosterone (NET 182: specific activity= $48.2 \mathrm{ci} / \mathrm{mmol}$; New England Nuclear) and a 1:20000 dilution of antibody (Endocrine Sciences:\#B3-163; Frye and Bayon, 1999; Frye et al, 1996). Dextran-coated charcoal was used to separate bound and free following a 15 -min incubation on ice and centrifugation at $3000 \mathrm{~g}$ for $10 \mathrm{~min}$. Supernatant was decanted into a glass scintillation vial with scintillation cocktail and then counted using a Tri-Carb 2000CA Liquid Scintillation Analyzer. Unknowns were interpolated from the standard curve using Assay Zap. The inter- and intra-assay reliability coefficients were 0.05 and 0.08 , respectively.

\section{Statistical Analyses}

In experiment 1 , two-way analyses of variance (ANOVAs) were utilized to examine effects of $E_{2}$ dosage and stress condition (no stress $v s$ restraint stress) on open field, elevated plus maze, and forced swim test behavior. Two-way ANOVAs were used to examine effects of $E_{2}$ dosage and stress condition (no stress and not tested, no stress and tested, or restraint stressed and tested) on plasma $\mathrm{E}_{2}$ and corticosterone levels. In experiment 2, two-way ANOVAs were also used to examine effects of $E_{2}$ dosage and ADX condition (sham, ADX + veh, ADX +25 corticosterone, and ADX +250 corticosterone) on open field, elevated plus maze, and forced swim test behavior, plasma corticosterone and $\mathrm{E}_{2}$ levels. Where appropriate, Fisher's post hoc tests were utilized to determine group differences. The $\alpha$ level for statistical significance was $p \leqslant 0.05$, and for a trend was $p \leqslant 0.10$. In all figures and text, data are expressed as the mean and standard deviation (SD).

\section{RESULTS}

\section{Plasma Estradiol Levels}

$\mathrm{E}_{2}$-primed ovx rats had significantly higher plasma $\mathrm{E}_{2}$ concentrations, such that $0,2<5<10<20<50 \mu \mathrm{g} \mathrm{E}_{2}$ produced higher plasma $E_{2}$ levels (see Table 1). There were no observable differences in $\mathrm{E}_{2}$ levels based upon which tasks the rats were tested in. There were no effects of restraint stress on plasma $\mathrm{E}_{2}$ levels.

As in the first experiment, administration of 0,10 , and $50 \mu \mathrm{g} \mathrm{E}_{2}$ produced statistically different plasma concentrations of $\mathrm{E}_{2}$ in these rats $(\mathrm{F}(2,106)=90.23, p<0.01$; see Table 2). There were no differences produced by ADX condition on these plasma $\mathrm{E}_{2}$ levels.

\section{Effects of $E_{2}$ Dosage and Stress on Anxiety Behavior}

Dosages of $\mathrm{E}_{2}(5$ or $10 \mu \mathrm{g})$ that produced moderate physiological plasma levels of $\mathrm{E}_{2}$ decreased anxiety behavior in the open field compared to vehicle and all other $E_{2}$ dosages administered. There was a significant effect of $E_{2}$ dosage on percentage of central entries in the open field $(\mathrm{F}(5,115)=17.12, p<0.01$; see Figure 1, left $)$ and duration spent by rats on the open arms of the plus maze $(\mathrm{F}(5,107)=5.28, p<0.01$; see Figure 2, left). Post hoc tests revealed that 5 or $10 \mu \mathrm{g} \mathrm{E}_{2}$, which produced plasma $\mathrm{E}_{2}$ levels within a moderate physiological range akin to levels observed during behavioral estrus (Frye and Bayon, 1999),
Table I Experiment I: Plasma Estradiol Levels $( \pm S D)$

\begin{tabular}{|c|c|c|c|}
\hline $\begin{array}{l}E_{2} \\
\text { dosage } \\
\text { ( } \mu \text { g/rat) }\end{array}$ & Stress condition & $n=$ & $\begin{array}{c}\text { Plasma } E_{2} \text { levels } \\
(\mathrm{pg} / \mathrm{ml})\end{array}$ \\
\hline \multirow[t]{3}{*}{0} & No stress and no testing & 3 & $0.8 \pm 0.7$ \\
\hline & No stress and testing & 5 & $1.6 \pm 0.6$ \\
\hline & Stress and testing & 8 & $1.4 \pm 0.5$ \\
\hline \multirow[t]{3}{*}{2} & No stress and no testing & 3 & $3.7 \pm 1.7$ \\
\hline & No stress and testing & 7 & $2.8 \pm 1.4$ \\
\hline & Stress and testing & 8 & $3.8 \pm 2.0$ \\
\hline \multirow[t]{3}{*}{5} & No stress and no testing & 3 & $27.7 \pm 3.8^{*}$ \\
\hline & No stress and testing & 6 & $15.0 \pm 4.8^{*}$ \\
\hline & Stress and testing & 5 & $14.0 \pm 4.4 *$ \\
\hline \multirow[t]{3}{*}{10} & No stress and no testing & 3 & $38.1 \pm 18.9 *$ \\
\hline & No stress and testing & 5 & $42.8 \pm 16.8 *$ \\
\hline & Stress and testing & 8 & $40.0 \pm 20.8 *$ \\
\hline \multirow[t]{3}{*}{20} & No stress and no testing & 3 & $72.6 \pm 16.2 *$ \\
\hline & No stress and testing & 6 & $68.0 \pm 15.0 *$ \\
\hline & Stress and testing & 7 & $63.6 \pm 14.7 *$ \\
\hline \multirow[t]{3}{*}{50} & No stress and no testing & 3 & $78.1 \pm 33.2 *$ \\
\hline & No stress and testing & 7 & $92.6 \pm 34.3^{*}$ \\
\hline & Stress and testing & 7 & $78.1 \pm 35.4 *$ \\
\hline
\end{tabular}

*Indicates a significant difference from all other dosages of $E_{2}(p<0.05)$.

Table 2 Experiment 2: Plasma Estradiol Levels ( $\pm S D$ )

\begin{tabular}{|c|c|c|c|}
\hline $\begin{array}{l}E_{2} \\
\text { dosage } \\
\text { ( } \mu \text { g/rat) }\end{array}$ & Stress condition & $n=$ & $\begin{array}{c}\text { Plasma } E_{2} \text { levels } \\
(\mathrm{pg} / \mathrm{ml})\end{array}$ \\
\hline \multirow[t]{4}{*}{0} & Sham & 10 & $1.0 \pm 0.4$ \\
\hline & $A D X+v e h$ & 8 & $1.4 \pm 0.5$ \\
\hline & $A D X+25$ CORT & 9 & $1.4 \pm 0.8$ \\
\hline & ADX+250 CORT & 8 & $1.6 \pm 0.7$ \\
\hline \multirow[t]{4}{*}{10} & Sham & 11 & $38.9 \pm 25.3^{*}$ \\
\hline & ADX+veh & 9 & $40.2 \pm 20.8^{*}$ \\
\hline & $A D X+25$ CORT & 12 & $50.4 \pm 24.7 * *$ \\
\hline & $A D X+250$ CORT & 12 & $47.4 \pm 26.8^{*}$ \\
\hline \multirow[t]{4}{*}{50} & Sham & 10 & $81.9 \pm 44.8 *$ \\
\hline & ADX+veh & 9 & $93.0 \pm 49.8^{*}$ \\
\hline & $\mathrm{ADX}+25 \mathrm{CORT}$ & 9 & $80.9 \pm 35.1 *$ \\
\hline & $A D X+250$ CORT & 11 & $92.7 \pm 26.1 *$ \\
\hline
\end{tabular}

*Indicates a significant difference from all other dosages of $E_{2}(p<0.05)$.

significantly increased central entries in the open field compared to vehicle $(0 \mu \mathrm{g})$, lower $(2 \mu \mathrm{g})$, and higher (20 and $50 \mu \mathrm{g}) \mathrm{E}_{2}$ dosages (all post hoc comparisons were $p<0.01$ ). There was a similar pattern in the plus maze, such that 5 or 


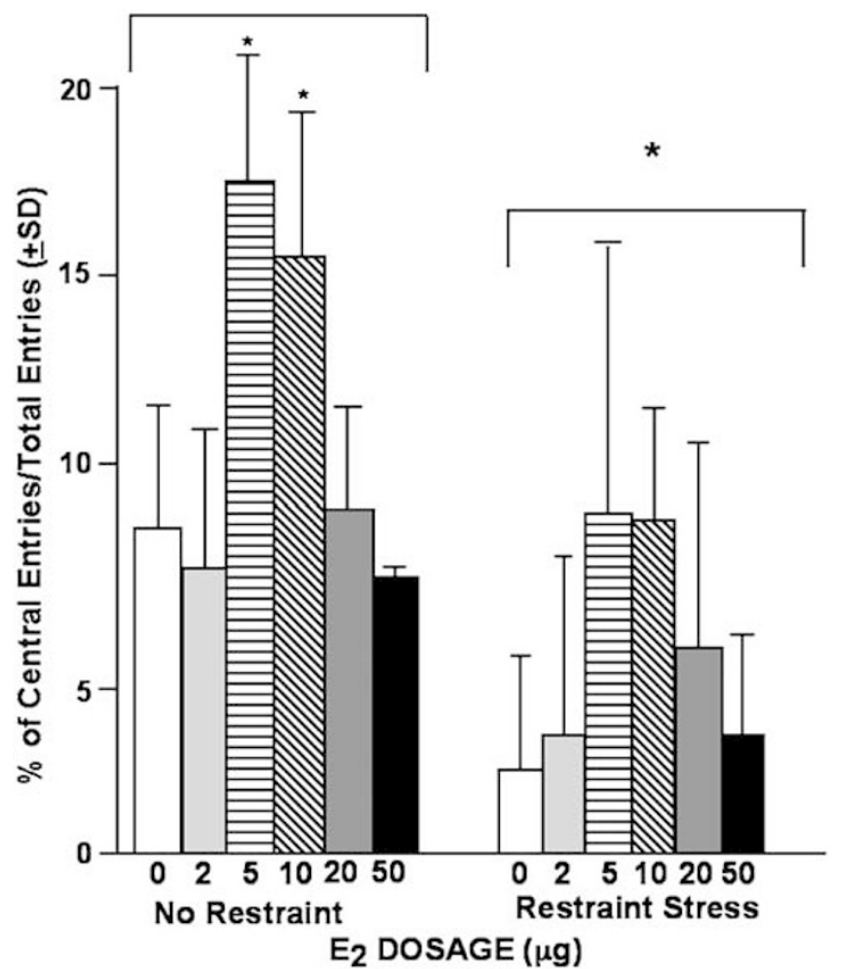

Figure I Effects of $E_{2}$ dosage and restraint stress on open field behavior. Rats were not stressed and administered $0(n=9), 2(n=11), 5(n=9), 10$ $(n=12), 20(n=9)$, or $50(n=10) \mu g E_{2}$ or stressed and administered 0 $(n=||), 2(n=||), 5(n=\mid 2), I 0(n=||), 20(n=||)$, or $50(n=||) \mu g$ $E_{2}$ before testing. *Above a single bar indicates that $E_{2}$ dosage is significantly different from all other $E_{2}$ dosages. *Above grouped bars indicates that restraint stress is significantly different from no stress condition.

$10 \mu \mathrm{g} \mathrm{E}_{2}$ increased duration spent by rats on the open arms compared to 0,2, 20, and $50 \mu \mathrm{g} \mathrm{E}_{2}$ (all post hoc comparisons were $p<0.01)$. There was a main effect of $\mathrm{E}_{2}$ dosage on total entries in the open field $(\mathrm{F}(5,115)=5.32, p<0.01)$. Post hoc tests revealed that $2(124.4 \pm 54.8), 5(142.0 \pm 55.6)$, or 10 $(138.3 \pm 50.2) \mu \mathrm{g} \mathrm{E}_{2}$ increased total entries compared to 0 $(85.0 \pm 39.0 ;$ vs $2 \mu \mathrm{g} p<0.01 ;$ vs $5 \mu \mathrm{g} p<0.01 ;$ vs $10 \mu \mathrm{g}$

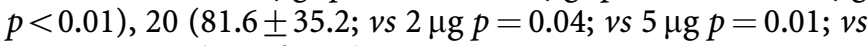
$10 \mu \mathrm{g} p<0.01)$, and 50 (90.7 $\pm 47.1 ; v s 2 \mu \mathrm{g} p<0.01$, vs $5 \mu \mathrm{g}$ $p<0.01 ; v s 10 \mu \mathrm{g} p<0.01) \mu \mathrm{g} \mathrm{E}_{2}$. However, there were no differences among groups for total entries in the plus maze (data not shown).

Restraint stress increased anxiety behavior of ovx rats compared to no restraint stress before testing. There was a significant effect of stress on total $(\mathrm{F}(1,115)=33.96, p<0.01)$ and percentage of central $(\mathrm{F}(1,115)=61.91, p<0.01$; see Figure 1, right) entries in the open field and time spent in the open arms of the elevated plus maze $(\mathrm{F}(1,107)=5.79$, $p<0.01$; see Figure 2, right). Post hoc tests revealed that $20 \mathrm{~min}$ of restraint stress immediately before behavioral testing significantly reduced central entries in the open field $(p<0.01)$, and tended to decrease open arm time $(p=0.07)$, compared to no restraint stress before testing. Restraint stress significantly reduced the total number of entries in the open field $(87.1 \pm 11.8)$ compared to no restraint stress before testing $(133.7 \pm 16.3 ; p<0.01)$. Restraint stress did not alter total entries in the plus maze (data not shown).

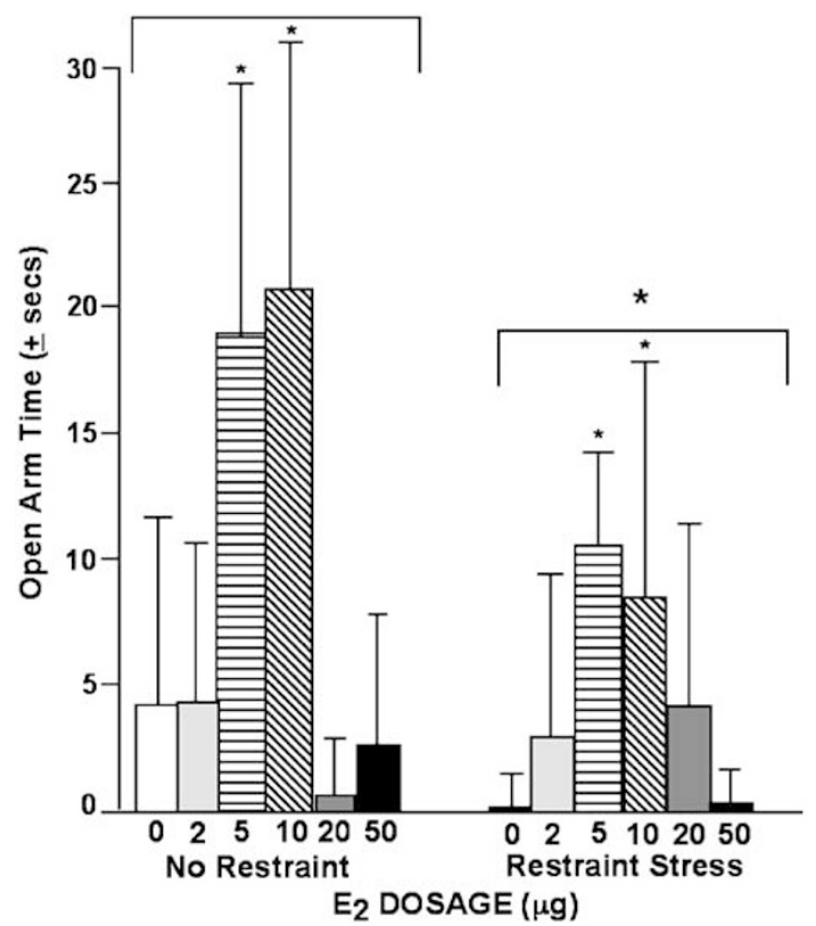

Figure 2 Effects of $E_{2}$ dosage and restraint stress on elevated plus maze behavior. Rats were not stressed and administered $0(n=9), 2(n=9), 5$ $(n=8), 10(n=7), 20(n=11)$, or $50(n=10) \mu \mathrm{g} E_{2}$ or stressed and administered $0(n=10), 2(n=12), 5(n=12), 10(n=12), 20(n=9)$, or $50(n=I I) \mu g E_{2}$ before testing. *Above a single bar indicates that $E_{2}$ dosage is significantly different from all other $E_{2}$ dosages. *Above grouped bars indicates that restraint stress is significantly different from no stress condition.

There was an interaction of $\mathrm{E}_{2}$ dosage and restraint stress on behavior in the open field. In the open field, restraint stress significantly decreased total $(\mathrm{F}(5,115)=2.28, p<0.05)$ and central $(\mathrm{F}(5,115)=6.91, p<0.01)$ entries of rats administered 5 or $10 \mu \mathrm{g} \mathrm{E}_{2}$, but not other $\mathrm{E}_{2}$ dosages, compared to no prior restraint stress. Rats that were restraint stressed prior to testing and administered 5 (90.1 \pm 44.2$), 10(103.2 \pm 45.7)$, but not $0(72.9 \pm 28.0), 2$ $(102.7 \pm 58.4), 20(95.4 \pm 25.5)$, or $50(72.8 \pm 28.0) \mu \mathrm{g} \mathrm{E} \mathrm{E}_{2}$, made significantly fewer total entries in the open field compared to rats that were not restraint stressed prior to testing and administered $5(198 \pm 67.0)$, or $10(173.3 \pm 54.6)$ $\mu \mathrm{g} \quad \mathrm{E}_{2}$, but not $0 \quad(97.1 \pm 49.9), \quad 2 \quad(146.0 \pm 51.2), \quad 20$ $(117.7 \pm 45.4)$, and $50(108.6 \pm 66.2) \mu \mathrm{g} \mathrm{E}_{2}$ (all post hoc comparisons were $p<0.01$ ).

In experiment 2, effects of $E_{2}$ dosages on anxiety behavior replicated findings from experiment 1 . There were significant effects of $E_{2}$ dosage on percentage of central entries $(\mathrm{F}(2,106)=10.43, p<0.01$; see Figure 3$)$ and the duration of time spent on the open arms of the plus maze $(\mathrm{F}(2,106)=16.42, p<0.01$; see Figure 4$)$. Post hoc tests revealed that $10 \mu \mathrm{g} \mathrm{E}_{2}$, which produced moderate physiological plasma $\mathrm{E}_{2}$ concentrations, significantly increased central entries in the open field and duration spent by rats on the open arms of the plus maze compared to vehicle $(0 \mu \mathrm{g})$ or $50 \mu \mathrm{g} \mathrm{E}_{2}$ (all post hoc comparisons were $p<0.01$ ). There was a main effect of $E_{2}$ dosage on total entries in the 


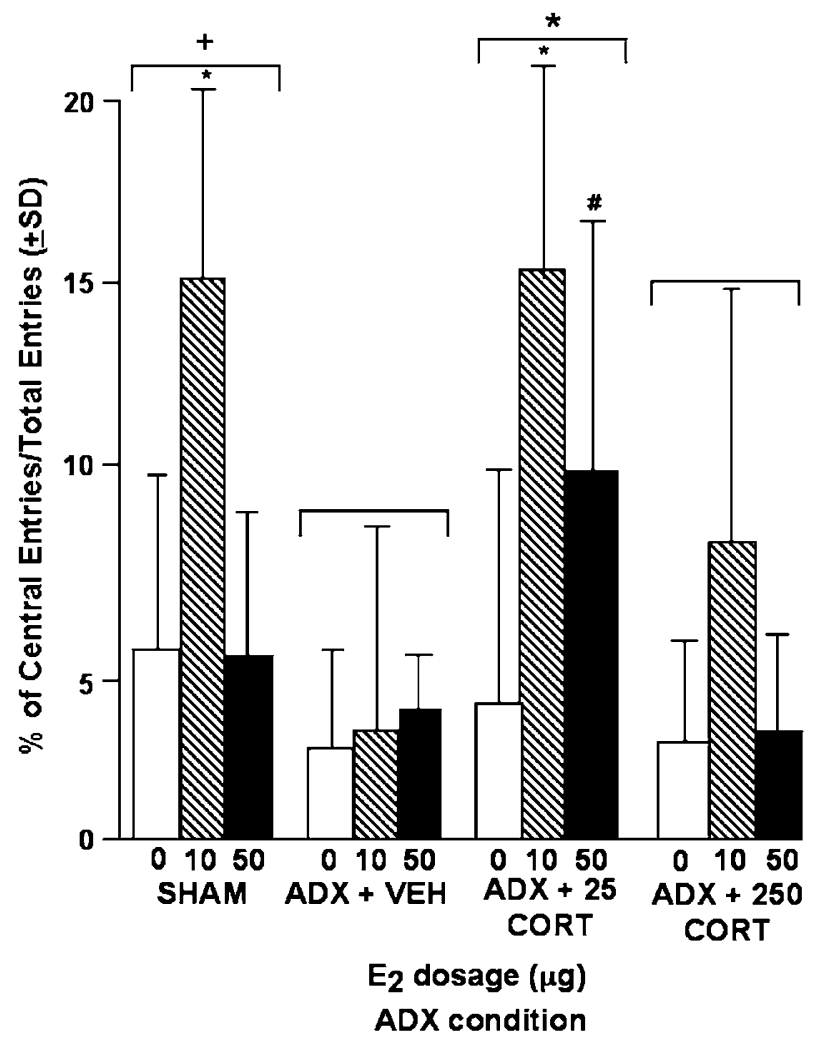

Figure 3 Effects of $E_{2}$ dosage and $A D X$ on open field behavior. Rats were sham surgerized and administered $0(n=10), 10(n=11)$, or 50 $(n=10) \mu g E_{2}, A D X+$ veh and administered $0(n=8), 10(n=9)$, or 50 $(n=9) \mu \mathrm{g} \mathrm{E}_{2}, \mathrm{ADX}+25 \mathrm{CORT}$ and administered $0(n=10), 10(n=9)$, or $50(n=\mid \mathrm{I}) \mu \mathrm{g} \mathrm{E}_{2}$, or ADX +250 CORT and administered $0(n=10)$, IO $(n=1 \mathrm{I})$, or $50(n=10) \mu \mathrm{g} \mathrm{E}_{2}$ before testing. *Above a single bar indicates that $E_{2}$ dosage is significantly different from all other $E_{2}$ dosages. \# above a single bar indicates that there is a tendency for $50 \mu \mathrm{g} E_{2}$ to be different from $0 \mu \mathrm{g} E_{2}$ condition. + Above grouped bars indicates that ADX condition is significantly different than ADX + veh condition. *Above grouped bars indicates that ADX condition is significantly different than $\mathrm{ADX}+$ veh and ADX + $250 \mathrm{CORT}$ condition.

open field $(\mathrm{F}(2,106)=7.70, p<0.01)$ and in the elevated plus maze $(F(2,106)=6.16, p<0.01)$. In the open field, 10 $(79.0 \pm 31.8)$ or $50(66.0 \pm 40.4) \mu \mathrm{g} \mathrm{E}_{2}$ significantly increased total entries compared to vehicle $(56.3 \pm 25.4$; all post hoc comparisons were $p<0.01)$. In the plus maze, $10(5.8 \pm 3.4)$ $\mu \mathrm{g} \mathrm{E}_{2}$ significantly increased total entries in the elevated plus maze compared to $0(3.8 \pm 1.6)$ and $50(4.5 \pm 2.0) \mu \mathrm{g} \mathrm{E}_{2}$ (all post hoc comparisons were $p<0.01$ ).

In experiment $2, \mathrm{ADX}$ altered anxiety behavior of rats. There were significant effects of ADX on percentage of central entries $(\mathrm{F}(3,107)=5.37, p<0.01$; see Figure 3$)$ and the duration of time spent on the open arms of the plus maze $(\mathrm{F}(3,107)=6.24, p<0.01$; see Figure 4$)$. Post hoc tests revealed that ADX rats administered $25 \mu \mathrm{g} / \mathrm{ml}$ corticosterone in their drinking water had significantly increased percentage of central entries in the open field compared to ADX rats administered vehicle or $250 \mu \mathrm{g} / \mathrm{ml}$ corticosterone in their drinking water (all post hoc comparisons were $p<0.01)$. In the plus maze, post hoc tests revealed that sham $\mathrm{ADX}$ rats and ADX rats administered $25 \mu \mathrm{g} / \mathrm{ml}$ corticosterone in their drinking water spent significantly more time on the open arms of the plus maze compared to rats

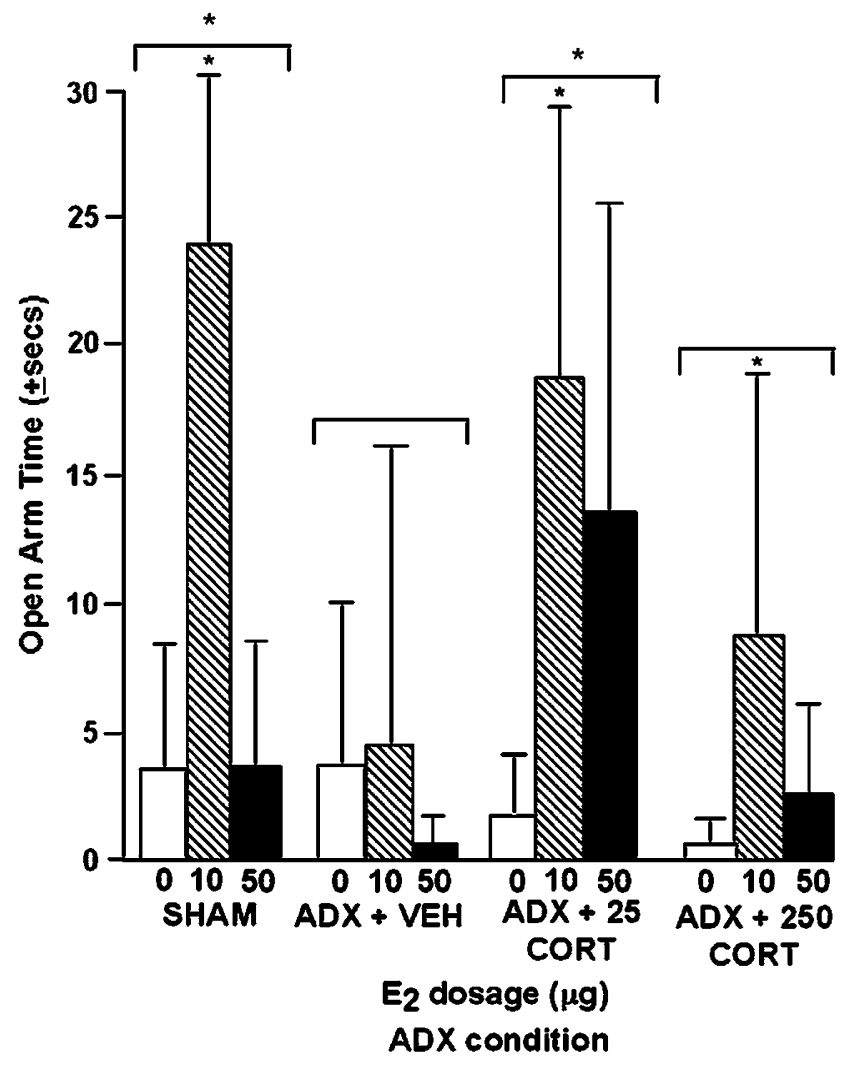

Figure 4 Effects of $E_{2}$ dosage and $A D X$ on elevated plus maze behavior. Rats were sham surgerized and administered $0(n=10), 10(n=11)$, or 50 $(n=10) \mu \mathrm{g} \mathrm{E}_{2}, \mathrm{ADX}+$ veh and administered $0(n=8), 10(n=9)$, or 50 $(n=9) \mu \mathrm{g} \mathrm{E}_{2}, \mathrm{ADX}+25 \mathrm{CORT}$ and administered $0(n=10), 10(n=9)$, or $50(n=\mid \mathrm{I}) \mu \mathrm{g} \mathrm{E}_{2}$, or ADX +250 CORT and administered $0(n=10)$, $10(n=11)$, or $50(n=10) \mu g E_{2}$ before testing. *Above a single bar indicates that $E_{2}$ dosage is significantly different from all other $E_{2}$ dosages. *Above grouped bars indicates that ADX condition is significantly different than ADX + veh and ADX + 250 CORT condition.

administered vehicle or $250 \mu \mathrm{g} / \mathrm{ml}$ corticosterone (all post hoc comparisons were $p<0.01$ ). Although there was no main effect of ADX on total entries in the open field (data not shown), there was a difference among groups for total entries in the plus maze $(\mathrm{F}(3,106)=3.67, p<0.01)$. Post hoc tests revealed that ADX rats administered $25 \mu \mathrm{g} / \mathrm{ml}$ corticosterone in their drinking water made more total entries $(6.0 \pm 2.7)$ in the plus maze than did ADX rats administered vehicle $(3.8 \pm 1.6 ; p=0.01)$ or $250 \mu \mathrm{g} / \mathrm{ml}$ corticosterone $(4.2 \pm 2.3 ; p<0.01)$ in their drinking water.

In the open field, there was a tendency for an interaction between $\mathrm{E}_{2}$ dosage and ADX condition. Although these data did not reach statistical significance, results suggest that $10 \mu \mathrm{g} \mathrm{E}_{2}$, compared to vehicle or $50 \mu \mathrm{g} \mathrm{E}_{2}$, increased percentage of central entries in sham and ADX rats administered $25 \mu \mathrm{g} / \mathrm{ml}$ corticosterone, but not ADX rats administered vehicle or $250 \mu \mathrm{g} / \mathrm{ml}$ corticosterone. Furthermore, there was a tendency for $50 \mu \mathrm{g} \mathrm{E}_{2}$ to increase central entries compared to rats administered $0 \mu \mathrm{g} \mathrm{E}_{2}$ in the group of ADX rats administered $25 \mu \mathrm{g} / \mathrm{ml}$ corticosterone only.

A similar pattern of effects was observed in the elevated plus maze. There was a significant interaction between $\mathrm{E}_{2}$ dosage and ADX condition $(\mathrm{F}(6,106)=3.16, p<0.01)$. Post hoc tests revealed that, compared to vehicle or $50 \mu \mathrm{g} \mathrm{E}_{2}$, 
$10 \mu \mathrm{g} \mathrm{E}_{2}$ increased time spent on the open arms of the plus maze in sham and ADX rats administered $25 \mu \mathrm{g} / \mathrm{ml}$ corticosterone, but not $\mathrm{ADX}$ rats administered vehicle or $250 \mu \mathrm{g} / \mathrm{ml}$ corticosterone (see Figure 4; all post hoc comparisons were $p<0.01$ ).

\section{Depressive Behavior}

Dosages of $\mathrm{E}_{2}(5$ or $10 \mu \mathrm{g})$ that produced moderate physiological plasma levels of $\mathrm{E}_{2}$ decreased depressive behavior in the forced swim test compared to vehicle and all other $\mathrm{E}_{2}$ dosages. There was a significant effect of $\mathrm{E}_{2}$ dosage on immobility $(\mathrm{F}(5,154)=19.92, p<0.01)$, struggling $(\mathrm{F}(5,154)=6.56, p<0.01)$, and swimming $(\mathrm{F}(5,154)=$ 9.10, $p<0.01)$ in the forced swim test. Post hoc tests revealed that 5 or $10 \mu \mathrm{g} \mathrm{E}_{2}$ significantly decreased duration of immobility in the forced swim test compared to vehicle or all other $\mathrm{E}_{2}$ dosages (see Figure 5, left; all post hoc comparisons were $p<0.01)$. Struggling and swimming were increased by administration of 5 (155.2 \pm 43.7 and $223.5 \pm 54.8)$ or $10(138.3 \pm 35.5$ and $236.0 \pm 62.5) \mu \mathrm{g}$ compared to $0(110.0 \pm 40.7$ and $159.3 \pm 45.0), 2(117.0 \pm 32.6$ and 187.8 \pm 58.1$), 20(131.5 \pm 40.7$ and $159.1 \pm 65.0)$, or 50 $(103.5 \pm 29.9$ and $170.7 \pm 57.1) \mu g \mathrm{E}_{2}$ (all post hoc comparisons were $p<0.01$ ).

Restraint stress increased depressive behavior of ovx rats compared to no restraint stress before testing. There was a significant effect of restraint stress on immobility $(\mathrm{F}(1,154)=67.63, \quad p<0.01)$, struggling $(\mathrm{F}(1,154)=5.67$, $p<0.01)$, and swimming $(\mathrm{F}(1,154)=45.99, p<0.01)$. Post hoc tests revealed that restraint stress significantly increased immobility in the forced swim test compared to no restraint stress (see Figure 5, right; $p<0.01$ ). Duration of struggling and swimming were also decreased in rats that were restraint stressed $(118.6 \pm 33.9$ and $158.8 \pm 59.2)$ compared to nonstressed rats $(133.1 \pm 40.4$ and $219.8 \pm 54.9$; all post hoc comparisons were $p<0.01)$.

There was an interaction of $\mathrm{E}_{2}$ dosage and restraint stress on immobility and swimming behavior in the forced swim test. Restraint stressed rats administered 5 or $10 \mu \mathrm{g} \mathrm{E}_{2}$ had significantly reduced duration of immobility $(\mathrm{F}(5,154)=2.31, \quad p<0.04$; see Figure 5) and increased swimming $(\mathrm{F}(5,154)=1.05, p<0.04)$ compared to rats administered vehicle or 2,20 , or $50 \mu \mathrm{g} \mathrm{E}_{2}$. For swimming behavior, rats that were restraint stressed and administered $5(181.1 \pm 59.3)$ or $10(183.4 \pm 72.8) \mu \mathrm{g} \mathrm{E}_{2}$, but not 0

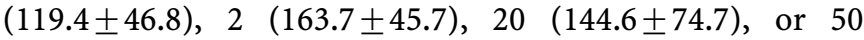
$(160.8 \pm 56.2) \mu \mathrm{g} \mathrm{E}_{2}$, had decreased swimming compared to nonstressed rats administered $5(265.9 \pm 50.4)$ or 10 $(288.5 \pm 52.1) \mu \mathrm{g} \mathrm{E}$, but not 0 (199.1 \pm 43.2$), 2(211.3 \pm 70.4)$, $20(173.5 \pm 55.3)$, or $50(180.5 \pm 58.0) \mu \mathrm{g} \mathrm{E}_{2}$ (all post hoc comparisons were $p<0.01)$.

In experiment $2, \mathrm{E}_{2}$ altered forced swim test behavior and replicated the pattern of results observed in experiment 1 . There was a significant effect of $\mathrm{E}_{2}$ dosage on immobility $(\mathrm{F}(2,106)=38.14, \quad p<0.01), \quad$ struggling $(\mathrm{F}(2,106)=4.48$, $p<0.01)$, and swimming $(\mathrm{F}(2,106)=7.65, p<0.01)$ in the forced swim test. Post hoc tests revealed that $10 \mu \mathrm{g} \mathrm{E}_{2}$ significantly decreased duration of immobility in the forced swim test compared to vehicle or $50 \mu \mathrm{g} \mathrm{E}_{2}$ (see Figure 6; $p<0.01) . \mathrm{E}_{2}(50 \mu \mathrm{g})$ significantly reduced duration of immobility compared to vehicle administration $(p<0.01)$,

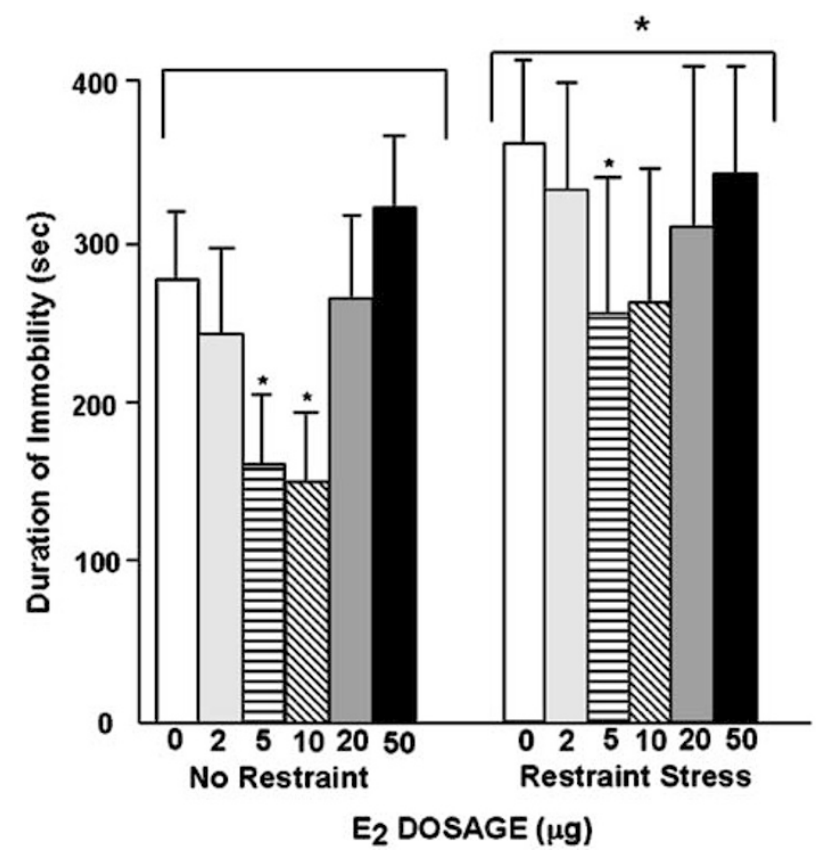

Figure 5 Effects of $E_{2}$ dosage and restraint stress on forced swim test behavior. Rats were not stressed and administered $0(n=15), 2(n=14), 5$ $(n=16), 10(n=17), 20(n=17)$, or $50(n=13) \mu \mathrm{g} E_{2}$ or stressed and administered $0(n=13), 2(n=12), 5(n=13), 10(n=11), 20(n=13)$, or $50(n=12) \mu g E_{2}$ before testing. *Above a single bar indicates that $E_{2}$ dosage is significantly different from all other $E_{2}$ dosages. *Above grouped bars indicates that restraint stress is significantly different from no stress condition.

$10 \mu \mathrm{g}(141.0 \pm 50.3$ and $200.1 \pm 66.9)$ similarly increased duration of struggling and swimming in the forced swim test compared to that observed in rats administered vehicle $(112.6 \pm 51.4$ and $143.9 \pm 54.5)$ or $50(125.6 \pm 43.3$ and $165.2 \pm 69.8) \mu \mathrm{g} \mathrm{E}_{2}$ (all post hoc comparisons were $p<0.01$ ).

ADX condition altered forced swim test behavior of rats. There was a significant effect of ADX on immobility $(\mathrm{F}(3,106)=19.12, \quad p<0.01)$, struggling $(\mathrm{F}(3,106)=2.85$, $p<0.04)$, and swimming $(\mathrm{F}(3,106)=4.42, p<0.01)$ in the forced swim test. Post hoc tests revealed that sham ADX rats and $\mathrm{ADX}$ rats administered $25 \mu \mathrm{g} / \mathrm{ml}$ corticosterone had significantly decreased duration of immobility in the forced swim test compared to vehicle or $250 \mu \mathrm{g} / \mathrm{ml}$ corticosteroneadministered ADX rats (see Figure 6; all post hoc comparisons were $p<0.01)$. Struggling behavior was significantly decreased by vehicle $(106.4 \pm 37.6)$ administration to $\mathrm{ADX}$ rats compared to $25(137.8 \pm 55.3)$ or 250 $(134.4 \pm 55.3) \mu \mathrm{g} / \mathrm{ml}$ corticosterone in their drinking water (all post hoc comparisons were $p<0.01$ ). Post hoc tests revealed the same pattern of effects for swimming behavior, as were observed for immobility. Sham (184.5 \pm 62.8$)$ and ADX rats administered $25(188.7 \pm 57.6) \mu \mathrm{g} / \mathrm{ml}$ corticosterone had significantly increased swimming behavior compared to ADX rats administered vehicle $(141.7 \pm 59.1)$ or 250 $(164.0 \pm 75.3) \mu \mathrm{g} / \mathrm{ml}$ corticosterone in their drinking water (all post hoc comparisons were $p<0.01$ ).

There were significant interactions between $E_{2}$ dosage and ADX condition for behavior in the forced swim test. There were significant interactions between $\mathrm{E}_{2}$ dosage and ADX condition on immobility $(\mathrm{F}(6,106)=8.53, p<0.01)$, 


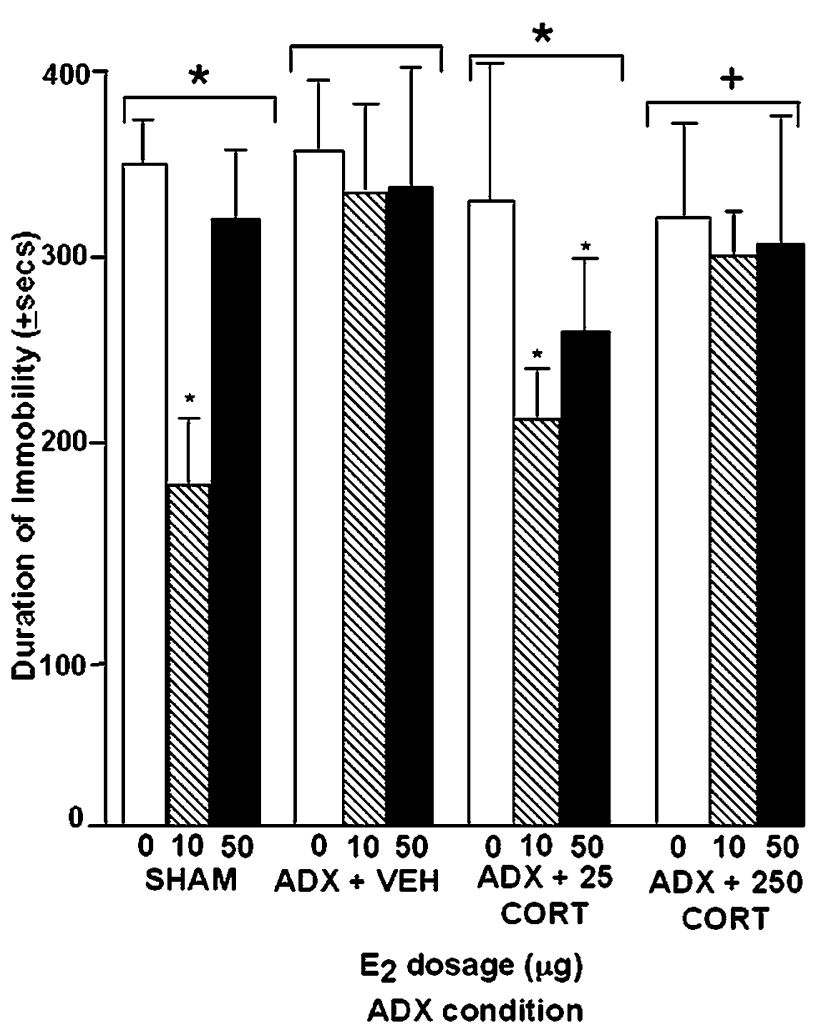

Figure 6 Effects of $E_{2}$ dosage and $A D X$ on forced swim test behavior. Rats were sham surgerized and administered $0(n=10), 10(n=11)$, or 50 $(n=10) \mu g E_{2}, A D X+$ veh and administered $0(n=8), 10(n=9)$, or 50 $(n=9) \mu g E_{2}, A D X+25$ CORT and administered $0(n=10), 10(n=9)$, or $50(n=\mid 1) \mu g E_{2}$, or ADX +250 CORT and administered $0(n=10)$, $10(n=11)$, or $50(n=10) \mu g E_{2}$ before testing. *Above a single bar indicates that $E_{2}$ dosage is significantly different from all other $E_{2}$ dosages. *Above grouped bars indicates that ADX condition is significantly different than ADX + veh and ADX + 250 CORT condition.

struggling $(\mathrm{F}(6,106)=3.10, \quad p<0.01)$, and swimming $(\mathrm{F}(6,106)=2.35, p<0.04)$ in the forced swim test. In all, $10 \mu \mathrm{g}$ decreased duration spent immobile in sham and ADX rats administered $25 \mu \mathrm{g} / \mathrm{ml}$ corticosterone, but not ADX rats administered vehicle or $250 \mu \mathrm{g} / \mathrm{ml}$ corticosterone, compared to vehicle or $50 \mu \mathrm{g} \mathrm{E}_{2}$ (see Figure 6; all post hoc comparisons were $p<0.01$ ). Rats administered $50 \mu \mathrm{g} \mathrm{E}_{2}$ had significantly decreased immobility, compared to rats administered $0 \mu \mathrm{g} \mathrm{E}_{2}$, in the group of ADX rats administered $25 \mu \mathrm{g} / \mathrm{ml}$ corticosterone only (all post hoc comparisons were $p<0.01$ ). For swimming behavior, $10 \mu \mathrm{g}$, but not vehicle or $50 \mu \mathrm{g}, \mathrm{E}_{2}$ increased duration spent swimming in sham $(240.7 \pm 7.35)$ and ADX rats administered $25(228.4 \pm 71.7) \mu \mathrm{g} / \mathrm{ml}$ corticosterone, but not ADX rats administered vehicle $(112.5 \pm 57.9)$ or $250(170.3 \pm 46.5) \mu \mathrm{g} / \mathrm{ml}$ corticosterone (all post hoc comparisons were $p<0.01$ ).

\section{Plasma Corticosterone Levels}

Dosages of $E_{2}$ that produced moderate physiological plasma levels of $E_{2}$ decreased plasma corticosterone levels. There was a significant main effect of $\mathrm{E}_{2}$ dosage on corticosterone levels $(\mathrm{F}(5,348)=46.77, p<0.01) . \mathrm{E}_{2}(5$ or $10 \mu \mathrm{g})$ significantly decreased plasma corticosterone levels compared to
Table 3 Experiment I: Plasma Corticosterone Levels ( \pm SD)

\begin{tabular}{|c|c|c|c|}
\hline $\begin{array}{l}E_{2} \\
\text { dosage } \\
\text { ( } \mu \text { g/rat) }\end{array}$ & Stress Condition & $\mathbf{n}=$ & $\begin{array}{c}\text { Plasma } \\
\text { corticosterone } \\
\text { levels }(\mu \mathrm{g} / \mathrm{dl})\end{array}$ \\
\hline \multirow[t]{3}{*}{0} & No stress and no testing & 16 & $5.0 \pm 0.9$ \\
\hline & No stress and testing & 20 & $5.3 \pm 0.7$ \\
\hline & Stress and testing & 25 & $5.1 \pm 0.6$ \\
\hline \multirow[t]{3}{*}{2} & No stress and no testing & 18 & $5.9 \pm 1.2$ \\
\hline & No stress and testing & 21 & $5.6 \pm 0.8$ \\
\hline & Stress and testing & 24 & $4.7 \pm 0.6$ \\
\hline \multirow[t]{3}{*}{5} & No stress and no testing & 16 & $2.3 \pm 0.3^{*}$ \\
\hline & No stress and testing & 21 & $2.2 \pm 0.3^{*}$ \\
\hline & Stress and testing & 26 & $3.9 \pm 0.4 *$ \\
\hline \multirow[t]{3}{*}{10} & No stress and no testing & 14 & $2.1 \pm 0.4^{*}$ \\
\hline & No stress and testing & 21 & $2.3 \pm 0.5^{*}$ \\
\hline & Stress and testing & 22 & $3.1 \pm 0.5 *$ \\
\hline \multirow[t]{3}{*}{20} & No stress and no testing & 16 & $8.1 \pm 2.0 *$ \\
\hline & No stress and testing & 18 & $12.9 \pm 1.7 * * * * *$ \\
\hline & Stress and testing & 25 & $10.7 \pm 1.3 * 3^{*}, * * * 1$ \\
\hline \multirow[t]{3}{*}{50} & No stress and no testing & 17 & $8.8 \pm 1.7 *$ \\
\hline & No stress and testing & 17 & $17.0 \pm 2.1^{*} * * * * *$ \\
\hline & Stress and testing & 29 & $14.9 \pm 1.4 * * * * *$ \\
\hline
\end{tabular}

* Indicates a significant difference from all other dosages of $E_{2}(p<0.05)$.

***indicates a significant effect of stress condition compared to other conditions $(p<0.05)$.

vehicle $(0 \mu \mathrm{g})$, lower $(2 \mu \mathrm{g})$, and higher $(20$ and $50 \mu \mathrm{g}) \mathrm{E}_{2}$ dosages (see Table 3); 20 and $50 \mu \mathrm{g} \mathrm{E}_{2}$ increased corticosterone levels compared to all other dosages, as revealed by post hoc tests (all post hoc comparisons were $p<0.01$ ).

Restraint stress, compared to the no stress and no testing condition, increased plasma corticosterone, but not $\mathrm{E}_{2}$, levels of rats. There was a significant effect of stress condition on plasma corticosterone levels $(\mathrm{F}(2,348)=2.67$, $p<0.01$; see Table 3 ), such that rats that were exposed to testing alone or with restraint had significantly higher plasma corticosterone levels than did rats that were not exposed to restraint stress or tested $(p<0.01)$.

Dosages of $\mathrm{E}_{2}(5$ or $10 \mu \mathrm{g})$ that produced moderate physiological plasma levels of $\mathrm{E}_{2}$ decreased basal, posttesting, and post-testing and restraint plasma corticosterone levels $(\mathrm{F}(10,348)=2.57, p<0.01$; see Table 3$) . \mathrm{E}_{2}$ ( 5 or $10 \mu \mathrm{g}$ ) significantly decreased corticosterone levels of rats that were not stressed or tested, as well as corticosterone levels after testing without prior restraint stress compared to vehicle $(0 \mu \mathrm{g})$, lower $(2 \mu \mathrm{g})$, and higher $(20$ and $50 \mu \mathrm{g}) \mathrm{E}_{2}$ dosages (all post hoc comparisons were $p<0.01$ ). Compared to vehicle or lower $E_{2}$ dosages, 20 or $50 \mu \mathrm{g} \mathrm{E}_{2}$ significantly increased basal, post-testing, and post-testing and restraint stress corticosterone levels (all post hoc comparisons were $p<0.01)$. 
Table 4 Experiment 2: Plasma Corticosterone Levels $( \pm S D)$

\begin{tabular}{llcc}
\hline $\begin{array}{l}\mathbf{E}_{\mathbf{2}} \\
\text { dosage } \\
(\boldsymbol{\mu g} / \mathbf{r a t})\end{array}$ & Stress condition & $\mathbf{n}=$ & $\begin{array}{c}\text { Plasma } \\
\text { corticosterone } \\
\text { levels (ng/dl) }\end{array}$ \\
\hline 0 & Sham & 10 & $6.7 \pm 5.9 *$ \\
& ADX+veh & 8 & $0.8 \pm 0.6$ \\
& ADX+25 CORT & 10 & $6.1 \pm 1.6 *$ \\
& ADX+250 CORT & 10 & $17.0 \pm 11.2 * *$ \\
10 & Sham & 11 & $3.3 \pm 3.9 *$ \\
& ADX+veh & 9 & $0.8 \pm 0.5$ \\
& ADX+25 CORT & 11 & $6.4 \pm 3.7 *$ \\
& ADX+250 CORT & 11 & $19.9 \pm 3.8 * *$ \\
& Sham & & $16.1 \pm 13.4 *$ \\
& ADX+veh & 10 & $0.9 \pm 0.5$ \\
& ADX+25 CORT & 9 & $7.3 \pm 1.4 *$ \\
& ADX+250 CORT & 9 & $17.3 \pm 9.9 * *$ \\
\hline
\end{tabular}

*Indicates that ADX condition is significantly different than ADX+veh and ADX+250 CORT condition ( $p<0.05)$.

***Indicates that ADX condition is significantly different than ADX+veh condition $(p<0.05)$.

Although there were no main effects of $E_{2}$ dosage on plasma corticosterone levels of sham and ADX rats, there were effects of ADX condition on plasma corticosterone levels $(\mathrm{F}(3,106)=24.73, p<0.01$; see Table 4$)$. Post hoc tests revealed that sham surgerized rats and ADX rats replaced with $25 \mu \mathrm{g} / \mathrm{ml}$ corticosterone had significantly higher corticosterone levels than did ADX rats administered vehicle, and significantly lower corticosterone levels compared to ADX rats administered $250 \mu \mathrm{g} / \mathrm{ml}$ corticosterone (all post hoc comparisons were $p<0.01$ ).

\section{DISCUSSION}

The present results support the hypotheses that $\mathrm{E}_{2}$ may have antianxiety and antidepressive effects, which may depend on $\mathrm{E}_{2}$ dosage, and be modulated by activity of the HPA. Ovx rats administered $\mathrm{E}_{2}$ dosages ( 5 or $10 \mu \mathrm{g}$ ) that produced moderate physiological levels of $\mathrm{E}_{2}$ entered significantly more central entries in the open field, spent significantly more time on the open arms of the plus maze, spent significantly less time immobile in the forced swim test, and had lower plasma corticosterone levels than did rats with lower or higher plasma $\mathrm{E}_{2}$ levels. Restraint stress before testing attenuated the antianxiety and antidepressive behavior of rats in these tasks and increased plasma corticosterone levels. In rats without an intact HPA, the effects of $10 \mu \mathrm{g} \mathrm{E}_{2}$ to reduce anxiety and depressive behavior were not observed, unless ADX rats were replaced with corticosterone that produced low plasma levels of corticosterone. Together, these data suggest that moderate $E_{2}$ levels, like that produced by 5 or $10 \mu \mathrm{g} \mathrm{E}_{2}$ administration, may decrease anxiety and depressive behavior and corti- costerone levels and that these effects may be modulated by the tone of the HPA.

The present results, that dosages of $\mathrm{E}_{2}$ that produced physiological levels of plasma $\mathrm{E}_{2}$ reduced anxiety behavior, confirm previous reports of $\mathrm{E}_{2}$ 's effects for affective behavior of rodents. Similar $\mathrm{E}_{2}$ regimen $(5-10 \mu \mathrm{g}$; SC), which likely also produced physiological plasma $\mathrm{E}_{2}$ levels, increased open field activity and time spent on the open arms of the plus maze, and decreased freezing in response to a footshock (Slater and Blizard, 1976; Frye and Walf, 2004a). However, some $E_{2}$ regimen of lower or higher $E_{2}$ dosages, or a longer duration of $E_{2}$ exposure, produce no effect on anxiety behavior, decrease anxiety behavior, or may indeed increase anxiety behavior of female rodents in these tasks (Diaz-Veliz et al, 1997; Luine et al, 1998; Martinez-Mota et al, 2000; Mora et al, 1996; Morgan and Pfaff, 2001, 2002; Nomikos and Spyraki, 1988; Stoffel and Craft, 2003). The present results that low dosages of $E_{2}$ $(<5 \mu \mathrm{g})$ were without effect, and that high dosages of $\mathrm{E}_{2}$ $(>10 \mu \mathrm{g})$ also did not have antianxiety effects, are consistent with this previous research. Together, these data from the present report suggest that $E_{2}$ 's effects on anxiety behavior may be sensitive to the $\mathrm{E}_{2}$ dosages and regimen employed, such that $\mathrm{E}_{2}$ dosages that produce physiological $\mathrm{E}_{2}$ levels $(5$ or $10 \mu \mathrm{g})$ produce antianxiety behavior in the open field and elevated plus maze tasks compared to lower $(0$ or $2 \mu \mathrm{g})$ or higher $(20$ or $50 \mu \mathrm{g}) \mathrm{E}_{2}$.

Our present results, that 5 or $10 \mu \mathrm{g} \mathrm{E}$, but not lower or higher $\mathrm{E}_{2}$ dosages, decreases immobility in the forced swim test support previous findings that $\mathrm{E}_{2}$ reduces depressive behavior of rodents. Similar to effects of $E_{2}$ on anxiety behavior, there is evidence for dose-dependent effects of $E_{2}$ on depressive behavior in the forced swim test. $\mathrm{E}_{2}$ regimen similar to the effective one utilized in this study $(5-10 \mu \mathrm{g})$ reduced immobility and increased swimming in the forced swim test of ovx rodents (Bernardi et al, 1989; EstradaCamarena et al, 2003; Hilakivi-Clarke, 1996; Rachman et al, $1998)$. However, $E_{2}$ to ovx voles, in a high dosage $(0.75 \mu \mathrm{g})$ that is sufficient to induce a lordosis response, but is not considered a supraphysiological dosage, did not reduce depressive behavior in the forced swim test (Galea et al, 2002). Moreover, administration of high dosages of $E_{2}$ $(50 \mu \mathrm{g})$ to rats for 4 days in an experimentally induced postpartum state (ie, withdrawal from high $E_{2}$ and progesterone levels akin to pregnancy) reduces immobility compared to vehicle administration in one, but not another, study (Galea et al, 2001; Stoffel and Craft, 2003). Although a low dosage of $\mathrm{E}_{2}(2 \mu \mathrm{g})$ administered $48 \mathrm{~h}$ before testing did not significantly increase $E_{2}$ levels of ovx rats at the time of testing and did not reduce immobility in the present study and another study, which utilized a similar regimen $(2.5 \mu \mathrm{g} /$ rat 1 or $48 \mathrm{~h}$ before testing; Estrada-Camarena et al, 2003), a longer exposure (2 weeks) to similar low dosages of $\mathrm{E}_{2}(0.3-$ $3.0 \mu \mathrm{g} / \mathrm{rat} /$ day) to ovx rats decreased immobility in the forced swim test (Okada et al, 1997). These data, and the present results, suggest that $E_{2}$ 's effects to reduce depressive behavior in the forced swim test of female rodents may be mitigated by the dosage and/or duration of $\mathrm{E}_{2}$ regimen utilized. Thus, $\mathrm{E}_{2}$ regimen that produced physiological $\mathrm{E}_{2}$ levels ( 5 or $10 \mu \mathrm{g}, 48 \mathrm{~h}$ before testing), but not regimen that produced lower $(0,2 \mu \mathrm{g})$ or higher $(20,50 \mu \mathrm{g}) \mathrm{E}_{2}$ levels, reduced depressive behavior in the forced swim. 
The results from the present study extend previous research of $\mathrm{E}_{2}$ 's effects for anxiety and depressive behavior by suggesting that these effects of $\mathrm{E}_{2}$ may be modulated by HPA responding. Restraint stress attenuated the antianxiety and antidepressive effects of 5 and $10 \mu \mathrm{g} \mathrm{E}_{2}$ to ovx rats. Moreover, plasma corticosterone levels of rats were lowest in ovx rats administered 5 or $10 \mu \mathrm{g} \mathrm{E}_{2}$, irrespective of stressors, such as testing and/or restraint. These data support previous findings that $10 \mu \mathrm{g} \mathrm{E}_{2}$ for 7 days reduced immobility in the forced swim task and reduced stress responses ( $c$-fos immunoreactivity in the hippocampus and amygdala, brain areas integral for affective behavior; Rachman et al, 1998). However, it must be noted that in the present study, the dosages of $\mathrm{E}_{2}$ that reduced immobility were administered in a more acute regimen of $48 \mathrm{~h}$ before testing. Furthermore, stress (or HPA activation) may alter rodents' response to gonadal hormones. This has been examined in an animal model of gestational stress. In addition to having a different pattern of corticosterone secretion compared to nongestationally stressed rats (Weinstock, 2001), gestationally stressed female rats may have reduced responsiveness to $\mathrm{E}_{2}$. For instance, female rats that are gestationally stressed and then tested as adults have decreased sexual behavior towards a male when naturally receptive or when $\mathrm{E}_{2}$-primed (Frye and Orecki, 2002a, b). Effects of $E_{2}$ replacement to reduce depressive behavior are attenuated in female gestationally stressed rats compared to controls (Frye and Wawrzycki, 2003). As well, gestationally stressed female, but not gestationally stressed male, rats have a reduced number of hippocampal granule cells, compared to effects observed in nongestationally stressed controls (Schmitz et al, 2002). Thus, the present findings that $\mathrm{E}_{2}$ 's effects to reduce anxiety and depressive behavior and corticosterone levels are attenuated by an acute stressor (restraint) substantiate these effects of gestational stress on behavioral and hormonal responses in female rodents.

The effects observed in this study for physiological $E_{2}$ concentrations to reduce anxiety and depressive behavior, which may be influenced by a prior stressor, are analogous to recent studies of $E_{2}$ 's biphasic effects on cognitive behavior among female rodents. Moderate, but not low or high, levels of $\mathrm{E}_{2}$ may improve cognitive performance (Shors and Leuner, 2003). Stressor exposure produces performance deficits among female rodents and this may be due to stress-induced elevations in plasma $\mathrm{E}_{2}$ levels (Shors et al, 1998, 1999; Shors and Leuner, 2003; Wood and Shors, 1998; Wood et al, 2001). However, chronic exposure of female rats, but not males, to a stressor has enhancing effects on cognitive performance (Bowman et al, 2001, 2002). Although the stress paradigm that we used in the present study did not increase $\mathrm{E}_{2}$ levels, effects of $\mathrm{E}_{2}$ were sensitive to the dosage administered and restraint stress reduced the antianxiety and antidepressive effects of moderate, physiological $\mathrm{E}_{2}$ levels.

The present results characterize some of the effects of different dosages of $E_{2}$ to ovx rats and manipulation of the HPA with pretesting restraint stress and ADX for anxiety and depressive behavior. We found an effect of moderate dosages $(5-10 \mu \mathrm{g})$, but not lower $(0-2 \mu \mathrm{g})$ or higher $(20-$ $50 \mu \mathrm{g})$ dosages, of $\mathrm{E}_{2}$ to reduce basal corticosterone levels and levels following behavioral testing with or without prior restraint. When the HPA was disrupted in rats with ADX, the ability of the moderate dose of $\mathrm{E}_{2}(10 \mu \mathrm{g})$ to reduce anxiety and depressive behavior was abrogated; however, $\mathrm{E}_{2}$ 's antianxiety and antidepressive effects were reinstated with replacement of low $(25 \mu \mathrm{g} / \mathrm{ml})$, but not high $(250 \mu \mathrm{g} /$ $\mathrm{ml}$ ), dosages of corticosterone. Unlike in experiment 1 , the dose-dependent effects of $\mathrm{E}_{2}$ to reduce anxiety and depressive behavior of rats did not have the same pattern of effects on plasma corticosterone levels. In experiment 2, $10 \mu \mathrm{g} \mathrm{E}_{2}$ reduces anxiety and depressive behavior of ADX rats replaced with $25 \mu \mathrm{g} / \mathrm{ml}$ corticosterone in their drinking water, but corticosterone levels of rats administered 0,10 , or $50 \mu \mathrm{g} \mathrm{E}_{2}$ were not different. This suggests that $\mathrm{E}_{2}$ 's effects on affective behavior cannot completely be explained by corticosterone levels.

There are complex effects of $\mathrm{E}_{2}$ and HPA interactions that may involve more than interactions of $\mathrm{E}_{2}$ and corticosterone. In our study, we grossly manipulated the HPA and replaced back corticosterone to determine whether $\mathrm{E}_{2}$ 's effects on antianxiety and antidepressive behavioral patterns require corticosterone. That $\mathrm{E}_{2}$ 's effects were absent in $\mathrm{ADX}$ rats suggest that $\mathrm{E}_{2}$ 's effects may be modulated by HPA feedback, but the nature of these effects were not completely revealed. That $\mathrm{E}_{2}$ 's antianxiety and antidepressive effects were reinstated in ADX rats with low dosage corticosterone-replacement suggests that some corticosterone may be necessary for $\mathrm{E}_{2}$ 's effects for these behaviors. Interestingly, there were differences in how much corticosterone-replacement was necessary for $E_{2}$ 's behavioral effects. There were different effects of low $v s$ high dose corticosterone replacement on $\mathrm{E}_{2}$ 's behavioral effects, which is consistent with variable reports of $E_{2}^{\prime}$ 's effects on corticosterone secretion in intact female rodents. For instance, during behavioral estrus, when $\mathrm{E}_{2}$ levels are typically high in female rodents, there is evidence for increased basal and stress-induced corticosterone secretion (Carey et al, 1995; Figueiredo et al, 2002; Frye and Bayon, 1999; Raps et al, 1971; Viau and Meaney, 1991), albeit there is variability within and between reports. Despite some evidence of higher corticosterone levels, proestrous rats also have reduced anxiety and depressive behavior compared to rats in other stages of estrous (Diaz-Veliz et al, 1997; Frye et al, 2000; Marcondes et al, 2001; Mora et al, 1996). Some of these variable effects may be due to differences in the stress reactivity of these animals and the type of stressor paradigm utilized and how stressful the behavioral task utilized is (reviewed in Herman et al, 2003). Interestingly, the dosedependent effects of $E_{2}$ that we observed in sham surgerized rats were less robust in $\mathrm{ADX}$, corticosterone-replaced rats. $\mathrm{E}_{2}(50 \mu \mathrm{g})$ produced similar effects as $10 \mu \mathrm{g} \mathrm{E}_{2}$ to reduce anxiety and depressive behavior in $\mathrm{ADX}$ rats that were replaced with a low dosage of corticosterone. Indeed, previous studies have demonstrated a complex relationship between $E_{2}$ and the HPA. As such, it would be important to examine effects of different dosages of $E_{2}$ on other indices of HPA activity, such as corticosteroid-binding globulin (CBG) and/or adrenocorticotropin (ACTH) levels, which also can be altered by gonadal hormones (Carey et al, 1995; Dayas et al, 2000; Figueiredo et al, 2003; McCormick et al, 2002; Viau and Meaney, 1991; Young et al, 2001), for these effects on anxiety and depressive behavior. Indeed, it has been suggested that $\mathrm{E}_{2}$ may sensitize adrenals to corticosterone secretion and have effects on HPA feedback via changing 
CBG and/or ACTH levels (Figueiredo et al, 2002, 2003). Thus, these effects further support that reductions in anxiety and depressive behavior may not be completely accounted for by changes in corticosterone levels per se.

$\mathrm{E}_{2}$ has been reported to enhance arousal of rodents, which may underlie some of the effects observed in the present study. For instance, $\mathrm{E}_{2}$ increases motor behavior of rodents (Colvin and Sawyer, 1969; Frye and Walf, 2004a; Morgan and Pfaff, 2001, 2002). However, profound effects of $E_{2}$ on gross motor behavior of rats cannot completely explain our present results of decreased anxiety and depressive behavior. A consistent effect of $\mathrm{E}_{2}$ on total entries in the open field or elevated plus maze or struggling and swimming in the forced swim test was not observed, but the changes observed in these indices suggests that some of the effects observed may be due to changes in arousal/ motor behavior following $\mathrm{E}_{2}$. Indeed, these alterations in arousal may be related to the effects of $E_{2}$ on HPA activity, but the extent to which $\mathrm{E}_{2}$ 's modulation of arousal is related to effects on HPA processes needs further attention.

The present data provide justification for further examining the nature and mechanisms by which $E_{2}$ and HPA activity interact for effects on anxiety and depressive behavior. First, although these data suggest involvement of the HPA at least for some of $\mathrm{E}_{2}$ 's effects on anxiety and depressive behavior, direct manipulation of this putative mechanism by pharmacological blockade of mineralocorticoid or glucocorticoid receptors would be of interest. Notably, $\mathrm{E}_{2}$ may have effects on distribution of glucocorticoid receptors in the brain (Patchev et al, 1995). Second, as discussed, it would also be of interest to examine the effects of $\mathrm{E}_{2}$ for altering other indices of HPA activity besides corticosterone. Further examination may reveal a more direct target of $\mathrm{E}_{2}$ on HPA activity, which would underlie the effects observed for anxiety and depressive behavior. For instance, the effects of $\mathrm{E}_{2}$ for the observed behavioral differences may be mediated by CBG, corticotropin releasing factor, and/or ACTH, which are also involved in modulating affective behavior (Almeida et al, 1997; Bale and Vale, 2003; Bale et al, 2000, 2002; Landgraf et al, 1999). Another possibility to consider is $\mathrm{E}_{2}$ 's effects on monoamines, such as serotonin, which also mitigate anxiety and depressive behavior and HPA activity, and may underlie the behavioral effects observed poststress and/or $\mathrm{E}_{2}$ administration (Bowman et al, 2003). Fourth, it is also important to consider the role that $\mathrm{E}_{2}$ has on progestins, which may underlie some of the effects observed. Progestins, particularly $5 \alpha$-reduced progestins, such as $5 \alpha$-pregnan- $3 \alpha$-ol-20one $(3 \alpha, 5 \alpha$-THP), modulate antianxiety and antidepressive behavior of female rodents (Frye et al, 2000, 2004; Frye and Walf, 2002, 2004b; Picazo and Fernandez-Guasti, 1995; Martinez-Mota et al, 2000; Rhodes and Frye, 2001). $\mathrm{E}_{2}$ enhances $3 \alpha, 5 \alpha$-THP formation by increasing $5 \alpha$-reductase activity and can enhance progestins' effects on behavior (Cheng and Karavolas, 1973; Frye and Duncan, 1996; Vongher and Frye, 1999). Notably, $5 \alpha$-reduced progestins may dampen HPA activity (Patchev and Almeida, 1996). Thus, although the present data suggest that $\mathrm{E}_{2}$ 's antianxiety and antidepressive behavioral effects may be mitigated by the HPA tone of the animal, and not corticosterone levels alone, the other modulating factors are not presently known.
In summary, rats administered $\mathrm{E}_{2}$ dosages $(5$ or $10 \mu \mathrm{g})$, which produced physiological plasma $\mathrm{E}_{2}$ concentrations, had significantly reduced anxiety (open field central entries, open arm duration in the plus maze) and depressive (immobility in the forced swim test) behavior and corticosterone levels compared to rats administered vehicle, lower $(2 \mu \mathrm{g})$, or higher $(20$ or $50 \mu \mathrm{g}) \mathrm{E}_{2}$ dosages. Restraint stress attenuated the antianxiety and antidepressive effects of $E_{2}$. ADX abrogated the effects of $E_{2}$ to reduce anxiety and depressive behavior, but these effects could be partially reversed by administration of 10 or $50 \mu \mathrm{g} \mathrm{E}_{2}$ in $\mathrm{ADX}$ rats replaced with a low, but not high, dosage of corticosterone. Thus, these data suggest that $\mathrm{E}_{2}$ may have dose-dependent effects on anxiety and depressive behavior of female rodents, in part through actions involving HPA responsiveness. Given that hormone-replacement therapy for women has recently come under fire (Rapp et al, 2003; Rossouw et al, 2002; Shumaker et al, 1998), these data that response to $E_{2}$ may be different depending on stress/HPA are important to consider. There is evidence that $\mathrm{E}_{2}$ can enhance mood of some women; however, there are differences in reports (Bjorn et al, 2003; Cohen et al, 2003; Halbreich, 1997; Morrison et al, 2004; Sherwin 1991, 1996; Schmidt et al, 1998, 2000; Soares et al, 2001). Indeed, the variable reports on the efficacy of $E_{2}$ replacement to influence anxiety or depression of women may in part involve individual differences in stress responsiveness related to past and/or current experiences.

\section{ACKNOWLEDGEMENTS}

This research was supported by grants from the National Science Foundation (98-96263; 03-16083). The technical assistance provided by Marie Rafalski is greatly appreciated.

\section{REFERENCES}

Almeida OF, Canoine V, Ali S, Holsboer F, Patchev VK (1997). Activational effects of gonadal steroids on hypothalamopituitary-adrenal regulation in the rat disclosed by response to dexamethasone suppression. J Neuroendocrinol 9: 129-134.

Bale TL, Contarino A, Smith GW, Chan R, Gold LH, Sawchenko PE et al (2000). Mice deficient for corticotropin-releasing hormone receptor-2 display anxiety-like behaviour and are hypersensitive to stress. Nat Genet 24: 410-414.

Bale TL, Picetti R, Contarino A, Koob GF, Vale WW, Lee KF (2002). Mice deficient for both corticotropin-releasing factor receptor 1 (CRFR1) and CRFR2 have an impaired stress response and display sexually dichotomous anxiety-like behavior. J Neurosci 22: 193-199.

Bale TL, Vale WW (2003). Increased depression-like behaviors in corticotropin-releasing factor receptor-2-deficient mice: sexually dichotomous responses. J Neurosci 23: 5295-5301.

Bebbington PE (1978). The epidemiology of depressive disorder. Cult Med Psychiatry 2: 297-341.

Bernardi M, Vergoni AV, Sandrini M, Tagliovini SB (1989). Influence of ovariectomy, estradiol and progesterone on the behavior of mice in an experimental model of depression. Physiol Behav 45: 1067-1068.

Bjorn I, Sundstrom-Poromaa I, Bixo M, Nyberg S, Backstrom G, Backstrom $T$ (2003). Increase of estrogen dose deteriorates mood during progestin phase in sequential hormonal therapy. J Clin Endocrinol Metab 88: 2026-2030. 
Bowman RE, Beck KD, Luine VN (2003). Chronic stress effects on memory: sex differences in performance and monoaminergic activity. Horm Behav 43: 48-59.

Bowman RE, Ferguson D, Luine VN (2002). Effects of chronic restraint stress and estradiol on open field activity, spatial memory, and monoaminergic neurotransmitters in ovariectomized rats. Neuroscience 113: 401-410.

Bowman RE, Zrull MC, Luine VN (2001). Chronic restraint stress enhances radial arm maze performance in female rats. Brain Res 904: 279-289.

Burgess LH, Handa RJ (1992). Chronic estrogen-induced alterations in adrenocorticotropin and corticosterone secretion, and glucocorticoid receptor-mediated functions in female rats. Endocrinology 131: 1261-1269.

Carey MP, Deterd CH, de Koning J, Helmerhorst F, de Kloet ER (1995). The influence of ovarian steroids on hypothalamicpituitary-adrenal regulation in the female rat. J Endocrinol 144: 311-321.

Cheng YJ, Karavolas HJ (1973). Conversion of progesterone to $5 \alpha$-pregnane-3,20-dione and $3 \alpha$-hydroxy-5 $\alpha$-pregnan-20-one by rat medical basal hypothalami and the effects of estradiol and stage of estrous cycle on the conversion. Endocrinology 93: $1157-1162$.

Cohen LS, Soares CN, Poitras JR, Prouty J, Alexander AB, Shifren JL (2003). Short-term use of estradiol for depression in perimenopausal and postmenopausal women: a preliminary report. Am J Psychiatry 160: 1519-1522.

Colvin GB, Sawyer CH (1969). Induction of running activity by intracerebral implants of estrogen in overiectomized rats. Neuroendocrinology 4: 309-320.

Conrad CD, Lupien SJ, Thanasoulis LC, McEwen BS (1997). The effects of type I and type II corticosteroid receptor agonists on exploratory behavior and spatial memory in the Y-maze. Brain Res 759: 76-83.

Dayas CV, Xu Y, Buller KM, Day TA (2000). Effects of chronic oestrogen replacement on stress-induced activation of hypothalamic-pituitary-adrenal axis control pathways. J Neuroendocrinol 12: 784-794.

Diaz-Veliz G, Alarcon T, Espinoza C, Dussaubat N, Mora S (1997). Ketanserin and anxiety levels: influence of gender, estrous cycle, ovariectomy and ovarian hormones in female rats. Pharmacol Biochem Behav 58: 637-642.

Diaz-Veliz G, Butron S, Benavides MS, Dussaubat N, Mora S (2000). Gender, estrous cycle, ovariectomy, and ovarian hormones influence the effects of diazepam on avoidance conditioning in rats. Pharmacol Biochem Behav 66: 887-892.

Earls F (1987). Sex differences in psychiatric disorders: origins and developmental influences. Psychiatr Dev 5: 1-23.

Estrada-Camarena E, Fernandez-Guasti A, Lopez-Rubalcava C (2003). Antidepressant-like effect of different estrogenic compounds in the forced swimming test. Neuropsychopharmacology 28: $830-838$.

Figueiredo HF, Dolgas CM, Herman JP (2002). Stress activation of cortex and hippocampus is modulated by sex and stage of estrus. Endocrinology 143: 2534-2540.

Figueiredo HF, Dolgas CM, Herman JP (2003). Dissociation of ACTH and corticosterone responses to stress in female rats treated with estrogen. Horm Behav 44: 48-49.

Frye CA, Bayon LE (1999). Mating stimuli influence endogenous variations in the neurosteroids $3 \alpha, 5 \alpha$-THP and $3 \alpha$-Diol. Neuroendocinology 11: 839-847.

Frye CA, Bayon LE, Pursnani NK, Purdy RH (1998). The neurosteroids, progesterone and $3 \alpha, 5 \alpha$-THP, enhance sexual motivation, receptivity, and proceptivity in female rats. Brain Res 808: 72-83.

Frye CA, Duncan JE (1996). Estradiol benzoate potentiates neuroactive steroids' effects on pain sensitivity. Pharmacol Biochem Behav 53: 27-32.
Frye CA, McCormick CM, Coopersmith C, Erskine MS (1996). Effects of paced and non-paced mating stimulation on plasma progesterone, $3 \alpha$-diol and corticosterone. Psychoneuroendocrinology 21: 431-439.

Frye CA, Orecki ZA (2002a). Prenatal stress produces deficits in socio-sexual behavior of cycling, but not hormone-primed, Long-Evans rats. Pharmacol Biochem Behav 73: 53-60.

Frye CA, Orecki ZA (2002b). Prenatal stress alters reproductive responses of rats in behavioral estrus and paced mating of hormone-primed rats. Horm Behav 42: 472-483.

Frye CA, Petralia SM, Rhodes ME (2000). Estrous cycle and sex differences in performance on anxiety tasks coincide with increases in hippocampal progesterone and $3 \alpha, 5 \alpha$-THP. Pharmacol Biochem Behav 67: 587-596.

Frye CA, Walf AA (2002). Changes in progesterone metabolites in the hippocampus can modulate open field and forced swim test behavior of proestrous rats. Horm Behav 41: 306-315.

Frye CA, Walf AA (2004a). Estrogen and/or progesterone systemically or to the amygdala can have anxiety, fear, and pain reducing effects in ovariectomized rats. Behav Neurosci 118: 306-313.

Frye CA, Walf AA (2004b). Hippocampal $3 \alpha, 5 \alpha$-THP may alter depressive behavior of pregnant and lactating rats. Pharmacol Biochem Behav 78: 531-540.

Frye CA, Walf AA, Rhodes ME, Harney JP (2004). Progesterone enhances motor, anxiolytic, analgesic, and antidepressive behavior of wild-type mice, but not those deficient in type 1 $5 \alpha$-reductase. Brain Res 1004: 116-124.

Frye CA, Wawrzycki J (2003). Effect of prenatal stress and gonadal hormone condition on depressive behaviors of female and male rats. Horm Behav 44: 319-326.

Galea LA, Lee TT, Kostaras X, Sidhu JA, Barr AM (2002). High levels of estradiol impair spatial performance in the Morris water maze and increase 'depressive-like' behaviors in the female meadow vole. Physiol Behav 77: 217-225.

Galea LA, Wide JK, Barr AM (2001). Estradiol alleviates depressive-like symptoms in a novel animal model of postpartum depression. Behav Brain Res 122: 1-9.

Glavas MM, Hofmann CE, Yu WK, Weinberg J (2001). Effects of prenatal ethanol exposure on hypothalamic-pituitary-adrenal regulation after adrenalectomy and corticosterone replacement. Alcohol Clin Exp Res 25: 890-897.

Halbreich U (1997). Hormonal interventions with psychopharmacological potential: an overview. Psychopharmacol Bull 33: 281-286.

Herman JP, Figueiredo H, Mueller NK, Ulrich-Lai Y, Ostrander MM, Choi DC et al (2003). Central mechanisms of stress integration: hierarchical circuitry controlling hypothalamopituitary-adrenocortical responsiveness. Front Neuroendocrinol 24: $151-180$

Hilakivi-Clarke L (1996). Role of estradiol in alcohol intake and alcohol-related behaviors. J Stud Alcohol 57: 162-170.

Jenkins R (1987). Sex differences in depression. Br J Hosp Med 38: 485-486.

Kessler RC, Walters EE (1998). Epidemiology of DSM-III-R major depression and minor depression among adolescents and young adults in the National Comorbidity Survey. Depress Anxiety 7: 3-14.

Kitay JL (1963). Pituitary adrenal function in the rat after gonadectomy and gonadal hormone replacement. Endocrinology 73: $2253-2260$.

Landgraf R, Wigger A, Holsboer F, Neumann ID (1999). Hyperreactive hypothalamo-pituitary-adrenocortical axis in rats bred for high anxiety-related behaviour. J Neuroendocrinol 11: 405-407.

Lewinsohn PM, Rohde P, Seeley JR (1998). Major depressive disorder in older adolescents: prevalence, risk factors, and clinical implications. Clin Psychol Rev 18: 765-794. 
Luine VN, Richards ST, Wu VY, Beck KD (1998). Estradiol enhances learning and memory in a spatial memory task and effects levels of monoaminergic neurotransmitters. Horm Behav 34: 149-162.

Maccari S, Darnaudery M, Morley-Fletcher S, Zuena AR, Cinque C, Van Reeth O (2003). Prenatal stress and long-term consequences: implications of glucocorticoid hormones. Neurosci Biobehav Rev 27: 119-127.

Marcondes FK, Miguel KJ, Melo LL, Spadari-Bratfisch RC (2001). Estrous cycle influences the response of female rats in the elevated plus-maze test. Physiol Behav 74: 435-440.

Martinez-Mota L, Estrada-Camarena E, Lopez-Rubalcava C, Contreras CM, Fernandez-Guasti A (2000). Interaction of desipramine with steroid hormones on experimental anxiety. Psychoneuroendocrinology 25: 109-120.

McCarthy MM, Felzenberg E, Robbins A, Pfaff DW, SchwartzGiblin S (1995). Infusions of diazepam and allopregnanolone into the midbrain central gray facilitate open-field behavior and sexual receptivity in female rats. Horm Behav 29: 279-295.

McCormick CM, Linkroum W, Sallinen BJ, Miller NW (2002). Peripheral and central sex steroids have differential effects on the HPA axis of male and female rats. Stress 5: 235-247.

McCormick CM, Rioux T, Fisher R, Lang K, MacLaury K, Teillon SM (2001). Effects of neonatal corticosterone treatment on maze performance and HPA axis in juvenile rats. Physiol Behav 74: 371-379.

Miller KJ, Conney JC, Rasgon NL, Fairbanks LA, Small GW (2002). Mood symptoms and cognitive performance in women estrogen users and nonusers and men. J Am Geriatr Soc 50: 1826-1830.

Mora S, Dussaubat N, Diaz-Veliz G (1996). Effects of the estrous cycle and ovarian hormones on behavioral indices of anxiety in female rats. Psychoneuroendocrinology 21: 609-620.

Morgan MA, Pfaff DW (2001). Effects of estrogen on activity and fear-related behaviors in mice. Horm Behav 40: 472-482.

Morgan MA, Pfaff DW (2002). Estrogen's effects on activity, anxiety, and fear in two mouse strains. Behav Brain Res 132: 85-93.

Morrison MF, Kallan MJ, Ten Have T, Katz I, Tweedy K, Battistini $M$ (2004). Lack of efficacy of estradiol for depression in postmenopausal women: a randomized, controlled trial. Biol Psychiatry 55: 406-412.

Nolen-Hoeksema S (1987). Sex differences in unipolar depression: evidence and theory. Psychol Bull 101: 259-282.

Nomikos GG, Spyraki C (1988). Influence of oestrogen on spontaneous and diazepam-induced exploration of rats in an elevated plus maze. Neuropharmacology 27: 691-696.

Okada M, Hayashi N, Kometani M, Nakao K, Inukai T (1997). Influences of ovariectomy and continuous replacement of $17 \beta$ estradiol on the tail skin temperature and behavior in the forced swimming test in rats. Jpn J Pharmacol 73: 93-96.

Patchev VK, Almeida OF (1996). Gonadal steroids exert facilitating and 'buffering' effects on glucocorticoid-mediated transcriptional regulation of corticotropin-releasing hormone and corticosteroid receptor genes in rat brain. J Neurosci 16: 7077-7084.

Patchev VK, Hayashi S, Orikasa C, Almeida OF (1995). Implications of estrogen-dependent brain organization for gender differences in hypothalamo-pituitary-adrenal regulation. FASEB J 9: 419-423.

Pellow S, File SE (1986). Anxiolytic and anxiogenic drug effects on exploratory activity in an elevated plus-maze as measure of anxiety in the rat. J Neurosci Methods 14: 149-167.

Picazo O, Fernandez-Guasti A (1995). Anti-anxiety effects of progesterone and some of its reduced metabolites: an evaluation using the burying behavior test. Brain Res 680: 135-141.

Porsolt R, LePichon M, Jalfre M (1977). Depression: a new animal model sensitive to antidepressant treatments. Nature 266: $730-732$.
Rachman IM, Unnerstall JR, Pfaff DW, Cohen RS (1998). Estrogen alters behavior and forebrain c-fos expression in ovariectomized rats subjected to the forced swim test. Proc Natl Acad Sci USA 95: 13941-13946.

Rapp SR, Espeland MA, Shumaker SA, Henderson VW, Brunner RL, Manson JE, et al, WHIMS Investigators (2003). Effect of estrogen plus progestin on global cognitive function in postmenopausal women: the Women's Health Initiative Memory Study: a randomized controlled trial. JAMA 289: 2663-2672.

Raps D, Barthe PL, Desaulles PA (1971). Plasma and adrenal corticosterone levels during the different phases of the sexual cycle in normal female rats. Experientia 27: 339-340.

Redei E, Li L, Halasz I, McGivern RF, Aird F (1994). Fast glucocorticoid feedback inhibition of ACTH secretion in the ovariectomized rat: effect of chronic estrogen and progesterone. Neuroendocrinology 60: 113-123.

Rhodes ME, Frye CA (2001). Inhibiting progesterone metabolism in the hippocampus of proestrous rats decreases anxiolytic, and enhances, exploration and analgesia. Cogn Affect Behav Neurosci 1: $287-296$

Rossouw JE, Anderson GL, Prentice RL, LaCroix AZ, Kooperberg C, Stefanick ML, et al, Writing Group for the Women's Health Initiative Investigators (2002). Risks and benefits of estrogen plus progestin in healthy postmenopausal women: principal results From the Women's Health Initiative randomized controlled trial. JAMA 288: 321-333.

Schmidt PJ, Nieman L, Danaceau MA, Tobin MB, Roca CA, Murphy JH et al (2000). Estrogen replacement in perimenopause-related depression: a preliminary report. Am J Obstet Gynecol 183: 414-420.

Schmidt PJ, Nieman LK, Danaceau MA, Adams LF, Rubinow DR (1998). Differential behavioral effects of gonadal steroids in women with and in those without premenstrual syndrome. $N$ Engl J Med 338: 209-216.

Schmitz C, Rhodes ME, Bludau M, Kaplan S, Ong P, Ueffing I et al (2002). Depression: reduced number of granule cells in the hippocampus of female, but not male, rats due to prenatal restraint stress. Mol Psychiatry 7: 810-813.

Seeman MV (1997). Psychopathology in women and men: focus on female hormones. Am J Psychiatry 154: 1641-1647.

Sherwin BB (1991). The impact of different doses of estrogen and progestin on mood and sexual behavior in postmenopausal women. J Clin Endocrinol Metab 72: 336-343.

Sherwin BB (1996). Hormones, mood, and cognitive functioning in postmenopausal women. Obstet Gynecol 87: 20S-26S.

Shors TJ, Leuner B (2003). Estrogen-mediated effects on depression and memory formation in females. I Affect Disord 74: 85-96.

Shors TJ, Lewczyk C, Pacynski M, Mathew PR, Pickett J (1998). Stages of estrous mediate the stress-induced impairment of associative learning in the female rat. NeuroReport 9: 419-423.

Shors TJ, Pickett J, Wood G, Paczynski M (1999). Acute stress persistently enhances estrogen levels in the female rat. Stress 3: 163-171.

Shumaker SA, Reboussin BA, Espeland MA, Rapp SR, McBee WL, Dailey $M$ et al (1998). The Women's Health Initiative Memory Study (WHIMS): a trial of the effect of estrogen therapy in preventing and slowing the progression of dementia. Control Clin Trials 19: 604-621.

Slater J, Blizard DA (1976). A reevaluation of the relation between estrogen and emotionality in female rats. J Comp Physiol Psychol 90: 755-764.

Soares CN, Almeida OP, Joffe H, Cohen LS (2001). Efficacy of estradiol for the treatment of depressive disorders in perimenopausal women: a double-blind, randomized, placebo-controlled trial. Arch Gen Psychiatry 58: 529-534.

Stoffel EC, Craft RM (2003). The effects of postpartum hormone withdrawal on depression and anxiety indices in female rats. 
Program No. 664.10.2003 Abstract Viewer/Itinerary Planner. Society for Neuroscience: Washington, DC. Online.

Tomie A, Silberman Y, Williams K, Pohorecky LA (2002). Pavlovian autoshaping procedures increase plasma corticosterone levels in rats. Pharmacol Biochem Behav 72: 507-513.

Torizuka K, Mizowaki M, Hanawa T (2000). Menopause and anxiety: focus on steroidal hormones and GABAA receptor. Nippon Yakurigaku Zasshi 115: 21-28.

Viau V, Meaney MJ (1991). Variations in the hypothalamicpituitary-adrenal response to stress during the estrous cycle in the rat. Endocrinology 129: 2503-2511.

Vongher JM, Frye CA (1999). Progesterone in conjunction with estradiol has neuroprotective effects in an animal model of neurodegeneration. Pharmacol Biochem Behav 64: 777-785.

Walf AA, Rhodes ME, Frye CA (2004). Anti-depressant effects of $\operatorname{ER} \beta$ selective estrogen receptor modulators in the forced swim test. Pharm Biochem Behav 78: 523-529.

Walf AW, Frye CA (2003). Anti-nociception following exposure to trimethylthiazoline, peripheral or intra-amygdala estrogen and/ or progesterone. Behav Brain Res 144: 77-85.

Weinstock M (2001). Alterations induced by gestational stress in brain morphology and behaviour of the offspring. Prog Neurobiol 65: 427-451.

Weissman MM, Klerman GL (1977). Sex differences and the epidemiology of depression. Arch Gen Psychiatry 34: 98-111.

Weissman MM, Olfson M (1995). Depression in women: implications for health care research. Science 269: 799-801.
Welberg LA, Seckl JR, Holmes MC (2000). Inhibition of 11 betahydroxysteroid dehydrogenase, the foeto-placental barrier to maternal glucocorticoids, permanently programs amygdala GR mRNA expression and anxiety-like behaviour in the offspring. Eur J Neurosci 12: 1047-1054.

Wittchen HU, Hoyer J (2001). Generalized anxiety disorder: nature and course. J Clin Psychiatry 62: 15-19.

Wood GE, Beylin AV, Shors TJ (2001). The contribution of adrenal and reproductive hormones to the opposing effects of stress on trace conditioning in males versus females. Behav Neurosci 115: 175-187.

Wood GE, Shors TJ (1998). Stress facilitates classical conditioning in males, but impairs classical conditioning in females through activational effects of ovarian hormones. Proc Natl Acad Sci USA 95: 4066-4071.

Young EA (1998). Sex differences and the HPA axis: implications for psychiatric disease. J Gend Specif Med 1: 21-27.

Young EA, Altemus M, Parkison V, Shastry S (2001). Effects of estrogen antagonists and agonists on the ACTH response to restraint stress in female rats. Neuropsychopharmacology 25: 881-891.

Young EA, Korszun A (2002). The hypothalamic-pituitarygonadal axis in mood disorders. Endocrinol Metab Clin North Am 31: 63-78.

Young EA, Midgley AR, Carlson NE, Brown MB (2000). Alteration in the hypothalamic-pituitary-ovarian axis in depressed women. Arch Gen Psychiatry 57: 1157-1162. 